\title{
MEASURING GROSS WORKER AND JOB FLOWS
}

Steven J. Davis

John Haltiwanger

Working Paper No. 5133

\section{NATIONAL BUREAU OF ECONOMIC RESEARCH 1050 Massachusetts Avenue \\ Cambridge, MA 02138 \\ May 1995}

Prepared for the NBER/CRIW project on Labor Statistics Measurement Issues. We thank Bruce Meyer for many helpful comments on a previous draft. Catherine Buffington and Lucia Foster provided excellent research assistance. The authors gratefully acknowledge research support provided by the National Science Foundation. Both authors are also research associates at the Center for Economic Studies, Bureau of the Census. This paper is part of NBER's research program in Labor Studies. Any opinions expressed are those of the authors and not those of the National Bureau of Economic Research.

(C) 1995 by Steven J. Davis and John Haltiwanger. All rights reserved. Short sections of text, not to exceed two paragraphs, may be quoted without explicit permission provided that full credit, including (C) notice, is given to the source. 


\title{
MEASURING GROSS WORKER \\ AND JOB FLOWS
}

\begin{abstract}
We combine information from several different studies and data sets to assemble a fuller, more accurate picture of job flows and worker flows in U.S. labor markets. Our picture characterizes the magnitudes of job and worker flows, the connections between them, their cyclical behavior, differences among identifiable groups of workers and employers, the spatial concentration of job flows, and other aspects of labor market dynamics. We also assess the relative strengths and weaknesses of the U.S. data sets that are currently available for measuring labor market flows, and we clarify the relationships among various measures of labor market flow activity that appear in the literature. Finally, we discuss prospects for using administrative records maintained by U.S. government agencies to develop new longitudinal data sets that would permit timely, detailed and comprehensive measures of gross job and worker flows.
\end{abstract}

Steven J. Davis

Graduate School of Business

University of Chicago

Chicago, IL 60637

and NBER
John Haltiwanger

Department of Economics University of Maryland College Park, MD 20742 and NBER 


\section{Introduction}

Market economies exhibit high rates of worker flows from one job to another and between employment and joblessness. The myriad forces that drive these flows fall into two broad categories: one associated with events or circumstances that induce workers to reallocate themselves among a given set of jobs and establishments, and a second associated with events that alter the distribution of available jobs among establishments.

The first category encompasses job-to-job movements for reasons of career advancement, family relocation, job satisfaction and quality of the worker-job match. It also encompasses labor force entry and exit for reasons of health, schooling, child-rearing, family relocation and retirement. The second category encompasses the many forces that impinge on the spatial distribution of labor demand including the growth and decline of markets, the restructuring of firms and industries, changing patterns of domestic and foreign competition, and local changes in costs and the business environment. These forces drive establishment-level job creation and destruction, which in turn cause workers to change employers and shuffle between employment and joblessness. In this way, the second category of forces gives rise to both job and worker flows.

This paper quantifies the magnitudes of job and worker flows, assesses the relative importance of the two broad categories of driving forces behind worker reallocation, and describes several key empirical regularities in the behavior of worker and job flows. We draw heavily on previous research to compile the empirical evidence, and we develop new evidence related to cyclical patterns in job and worker flows.

Previous studies use a variety of household, worker, establishment, and firm data sets to examine specific aspects of worker and job flows. Because there is no comprehensive source of information on worker and job flows in the U.S. economy, it is necessary to draw upon several different studies and data sets to assemble a fuller, more accurate picture of labor market flows. A vailable data sets differ, often greatly, in terms of sampling frequency, sampling unit, time period, and extent of regional and industrial coverage. We discuss these differences and assess the relative strengths and weaknesses of the available data sets. The worker and job flow concepts that can be measured also differ greatly among available data sets, sometimes in subtle ways. To clarify these differences, we spell out the relationships among alternative measures that appear in the literature.

In the concluding section, we discuss prospects for the development of new longitudinal employer-level data sets that would permit timely, detailed and comprehensive measures of gross job flows. In this regard, we consider two sources of administrative records maintained by the U.S. government. Since these administrative records are already in place and are 
collected on an ongoing basis, they offer a relatively low-cost vehicle for the construction of gross job flow statistics. We also discuss a third source of administrative records that holds open the promise of comprehensive, linked statistics on job flows and worker flows.

We offer a few additional road signs to the organization of the paper. Section II outlines several reasons to measure and study gross worker and job flows. Section III defines worker and job flow measures used in previous studies, spelling out the relationships among them. Section IV describes the main U.S. sources of data on the various measures of worker flows and job flows. Section V compiles the evidence and synthesizes much of what we know about the empirical behavior of U.S. worker flows and job flows. Section VI summarizes this synthesis in a bare-bones recital of facts and empirical regularities. Section VII describes prospects for new sources of data on U.S. worker flows and job flows.

\section{Why Measure and Study Gross Worker and Job Flows?}

There are many reasons to measure gross worker and job flows and to study their behavior. We sketch out a dozen reasons here. As a by-product, we draw attention to areas of research that exploit or have been stimulated by gross flow statistics, and we identify other potentially fruitful applications of data on labor market flows.

1. The two broad categories of driving forces behind gross worker flows identified in the introduction lead to different theories of worker mobility. The first category leads to a focus on job-shopping, match quality and events that affect preferences regarding work. The second category leads to a focus on demand-side disturbances that induce shifts in the distribution of job opportunities across locations. Quantifying the relative importance of each set of reasons for worker flows - and measuring how the relative importance differs among groups of workers, among types of employers, and over time - helps to direct theorizing and policy-making about worker mobility behavior and related phenomena.

2. The magnitude of gross worker and job flows sheds light on the plausibility of alternative theories of unemployment and wage determination. For example, the large magnitude of gross job flows documented in previous studies underscores the empirical relevance of theories that model unemployment as a frictional phenomenon, i.e., as a consequence of continual shifts in the structure of labor demand. By the same token, 
high rates of worker and job flows in all market economies and almost every industry and type of firm diminish the empirical relevance of theories that stress conflicts between static groups of employed insiders and jobless outsiders. ${ }^{1}$

3. Many economic theories deal with assignment problems that arise when workers are imperfect substitutes in production, or when they differ in their ability or desire to work with cooperating factors. Assignment models underlie the analysis of several important topics in labor economics including dual labor markets, equalizing differences in wage payments, labor market sorting based on comparative and absolute advantage, and the organization of workers into teams and hierarchies - see Sattinger (1993). Worker and job flows across locations are among the most important mechanisms by which the economy continually adjusts the assignment of workers to each other and to cooperating factors of production.

4. Job flow statistics shed light on the reasons for differences in job tenure distributions across industries, among different types of firms, and over time. For example, pronounced differences in job destruction rates probably account for much of the differences in job tenure distributions by size of employer. Linked measures of worker and job flows would be especially useful for understanding why tenure distributions differ among groups of workers and how these differences relate to interactions between individual and employer characteristics.

5. Data on the geographic incidence and concentration of gross job flows greatly facilitate the study of wage and employment spillovers in local labor markets. Such data could be combined with information on defense contract awards, for example, to identify job creation and destruction events that are exogenous to local labor markets. One could then examine the impact of job creation and destruction events on wages, employment, gross worker flows, population and the tax base in nearby and more distant labor markets.

6. Cross-sectional evidence on gross job flows sheds light on the life-cycle dynamics of establishment-level and firm-level employment. For example, Davis and Haltiwanger (1992) find a strong, pervasive pattern of higher gross job flow rates at younger plants. This ubiquitous pattern highlights the connection between employer age and heterogeneity, and it provides strong support for the importance of selection effects in the evolution of industries and plants (Jovanovic, 1982).

${ }^{1}$ Davis, Haltiwanger and Schuh (1995) provide considerable evidence on the prevalence of large-scale job and worker flows in the United States. OECD (1994, chapter 3) reviews the international evidence. 
7. Recent studies by Olley and Pakes (1992) and Baily, Bartelsman and Haltiwanger (1994) find that the reallocation of jobs and factor inputs from less efficient to more efficient plants accounts for a large fraction of industry-level productivity gains. More generally, data on gross job flows provide a tool for studying the connection between the reallocation process and the growth of productivity and wages.

8. Time-series data on gross flows shed new light on the nature of business cycles and provide a window into the connection between recessions and the reallocation of workers and jobs. For example, data for the U.S. manufacturing sector indicate that recessions are characterized by sharp jumps in job destruction rates but little change in job creation rates (Davis and Haltiwanger, 1990, Davis, Haltiwanger and Schuh, 1995). Davis, Haltiwanger and Schuh (1994) develop evidence that this pattern holds in the U.S. manufacturing sector for every recession since $1937 .^{2}$

9. Evidence on the time-series properties of gross job flows has helped stimulate and guide a resurgence of research on dynamic equilibrium theories of the search and reallocation process and its connection to aggregate fluctuations. Prominent examples include work by Blanchard and Diamond (1990), Caballero and Hammour (1994a), Mortensen (1992), and Mortensen and Pissarides (1993).

10. Time-series data on gross job flows provide a new source of leverage for drawing inferences about the driving forces behind aggregate economic fluctuations. See, for example, Davis and Haltiwanger (1994) and Caballero, Engel and Haltiwanger (1994).

11. The pervasiveness and magnitude of large-scale gross job flows underscore the dangers of reasoning about aggregate and industry-level dynamics from representativeemployer models. Large-scale heterogeneity among employers implies considerable scope for aggregation to smooth away even pronounced nonlinearities and asymmetries in firm-level and establishment-level employment dynamics. See Caballero (1992) and Hamermesh (1993, chapter 7). Furthermore, gross job flow data point to considerable lumpiness in establishment-level employment changes. Lumpiness and heterogeneity imply that aggregate employment dynamics are closely intertwined with the evolution of the cross-sectional distribution of establishment-level employment changes. See, for example, Caballero and Engel (1993).

12. Data on gross job flows have proved useful as inputs into quantitative theoretical analyses of firing costs (Hopenhayn and Rogerson, 1993), the welfare implications of

${ }^{2}$ As yet, available evidence is too sparse to confidently judge the prevalence of this pattern across industries and countries. 
aggregate business cycles (Caballero and Hammour, 1994b), and the efficiency of the reallocation process (Mortensen, 1994).

\section{Concepts and Definitions}

Section II offers motivation for measuring and studying gross worker and job flows. In this section, we define several measures that have been adopted in previous work, and we spell out the relationships among them.

\section{A. Worker Flow Measures}

We begin by defining a measure of gross worker reallocation:

Gross worker reallocation at time $t$ equals the number of persons whose place of employment or employment status differs between $t-1$ and $t$.

A change in employment status means a transition from employment to nonemployment, or vice versa. Gross worker reallocation can be measured by counting the number of persons who have either a different employment status or a different place of employment between two points in time.

It is important to distinguish this concept of gross worker reallocation from a widely used measure of worker turnover:

Total turnover at time $t$ equals the number of accessions plus the number of separations that occur during the interval from $t-1$ to $t$.

Total turnover measures the gross number of labor market transitions, whereas gross worker reallocation measures the number of persons who participate in transitions. Differences between these two measures of labor market flows arise for two reasons. First, job-to-job movements induce twice as much total turnover as worker reallocation. To see this point, consider the example of two workers who exchange jobs and employers. Under the total turnover measure, this example involves four transitions: two separations and two accessions. Under the gross worker reallocation measure, two workers participate in the transitions. Other patterns of labor market flows induce equal-sized increments to total turnover and worker reallocation. For example, consider an unemployed and an employed worker who switch positions. This event involves two transitions - one separation and one accession - but it also involves two individuals.

A second difference arises from the different sampling methods that are often used to measure these two concepts of labor market flows. Some total turnover measures - e.g., 
the well-known BLS turnover series - encompass all separations and accessions that occur during an interval of time. For example, if an individual is employed at the beginning of the time interval, but undergoes a completed spell of temporary layoff and recall during the interval, that worker contributes two transitions to the total turnover measure: one separation and one accession. ${ }^{3}$ In contrast, gross worker reallocation measures are typically based on changes in employment status and place of employment between two discrete points in time. Hence, the worker in the previous example contributes nothing to the measure of gross worker reallocation, because he holds the same employment position at the beginning and end of the sampling interval.

The conceptual differences between gross worker reallocation and total turnover appear not to have been fully appreciated in the recent literature. Anderson and Meyer (1994) and Lane, Isaac, and Stevens (1993) construct total turnover measures, but they treat their measures as analogous to the measure of gross worker reallocation calculated by Davis and Haltiwanger (1992). The preceding remarks make clear that total turnover and gross worker reallocation are not analogous.

However, there is something to be learned by comparing the two quantities. To the extent that one can ignore or delete accessions and separations that are reversed within the sampling interval, the difference between total turnover and gross worker reallocation equals the number of job-to-job transitions that occur during the sampling interval. One can imagine using data on temporary layoffs and recalls to "correct" total turnover for the accessions and separations that are reversed within the interval. ${ }^{4}$ Absent such a correction, one can still interpret the difference between total turnover and worker reallocation as an upper bound on the number of job-to-job transitions that occur during the interval.

\footnotetext{
${ }^{3}$ The definition of total turnover stated in the text corresponds precisely to the sum of separations plus accessions as measured in the BLS turnover data, but it corresponds imperfectly to some other measures that appear in the literature under the name of turnover or job turnover. For example, Anderson and Meyer (1994) use a measure of turnover that picks up some, but not all, of the layoff-recall events that are completed within the sampling interval. The turnover measure used by Lane, Isaac and Stevens (1993) does not include any layoffs that are reversed within the sampling interval.

${ }^{4}$ Temporary layoffs and recalls are likely to be the main source of separations and accessions that are reversed within the sampling interval.
} 


\section{B. Job Flow Measures}

Much of this paper decomposes worker flows along a different line. As suggested in the introduction, there are two broad sets of driving forces behind gross worker reallocation one associated with job reallocation, and one associated with worker reallocation among a fixed set of jobs. To develop this decomposition, we begin by defining measures of gross job flows:

Gross job creation at time $t$ equals employment gains summed over all establishments that expand or startup between $t-1$ and $t$.

Gross job destruction at time $t$ equals employment losses summed over all establishments that contract or shut down between $t-1$ and $t$.

Gross Job Reallocation at time $t$ equals the sum of all establishment-level employment gains and losses that occur between $t-1$ and $t$. It equals the sum of job creation and destruction.

Because they are cumulated from net establishment-level employment changes, these job flow measures omit job reallocation that takes the form of changes in the mix of employment positions within establishments. In this respect, the job flow measures share a feature of the gross worker reallocation and total turnover measures, neither of which directly encompass internal labor mobility. Hence, all of the labor flow measures considered in this paper can be viewed as lower bounds on conceptually similar, but broader and more encompassing measures.

However, at least some changes in the mix of jobs within establishments are likely to induce separations and accessions that enter into the measures of total turnover and gross worker reallocation. In this respect, the worker reallocation and total turnover measures are more inclusive than the job flow measures. Put another way, the gross job flow measures miss a portion of the changes in the structure of labor demand that underlie the demanddriven component of measured worker reallocation and total turnover. This matter seems minor, and we ignore it in the remainder of the paper.

\section{Quantifying the Connection between Worker Flows and Job Flows}

Given data that matches workers to their employers and follows each over time, one can directly quantify the connection between worker flows and job flows. For example, one can calculate the fraction of worker accesssions accounted for by job creation and the fraction of worker separations accounted for by job destruction. To the extent that such 
data encompass the entire economy - thereby precluding worker transitions into or out of the covered sector - one can directly calculate the fraction of gross worker reallocation accounted for by job reallocation. Lane et al (1993) and Anderson and Meyer (1994) carry out such calculations using U.S. data, and Albaek and Sorensen (1995) do so using Danish data. While the data requirements are demanding, matched worker-employer longitudinal data make it feasible to precisely characterize the relationship between worker flows and job flows and to study changes over time and differences in this relationsip among groups of workers and employers. As we discuss below in section VII, there are prospects for constructing comprehensive matched worker-employer data for the United States.

In the absence of suitable matched worker-employer data, one can place bounds on the amount of worker reallocation induced by the reshuffling of job opportunities as follows. Job reallocation equals the maximum amount of worker reallocation directly induced by the reshuffling of employment opportunities across locations. We say the "maximum amount," because some job-losing workers move from a shrinking establishment to a new job at a growing establishment within the sampling interval. Such workers are counted twice in the job reallocation measure - once in the job destruction column and once in the job creation column. To eliminate any possibility of double counting in quantifying the link between job and worker reallocation, we use the following measure:

Minimum worker reallocation equals the larger of job creation or job destruction. It represents a lower bound on the amount of worker reallocation required to accommodate job reallocation.

Similarly, by subtracting job reallocation and minimum worker reallocation from the gross worker reallocation measure, one obtains bounds on the number of workers who engage in reallocation among a given set of jobs and establishments. ${ }^{5}$

In short, we can assess the relative importance of the two broad categories of driving forces behind worker reallocation by combining independent data on worker flows and job flows. Data on worker flows provide a count of the number of workers who make labor

${ }^{5}$ We recognize that not all job flows cleanly reflect changes in the spatial structure of labor demand. Suppose, for example, that a well-matched worker quits because of a change in personal circumstances, and that the employer chooses not to replace the worker because the expected net return from a new match is too low. In this scenario, the job flow event triggered by the quit reflects elements of both job matching and job reallocation. In practice, we count such events as worker reallocation induced by job reallocation. 
market transitions; data on job flows provide bounds on the number of such transitions that occur because of changes in the spatial structure of labor demand.

To accurately assess the relative magnitude of the driving forces behind these transitions, it is essential to measure worker flows and job flows in comparable ways. The worker reallocation and gross job flow measures defined above involve changes in employment status, place of employment, or number of employees between two discrete points in time. In practice, we compare worker flows and job flows computed over sampling intervals of equal length.

This discussion should also make clear that comparisons between total worker turnover and job reallocation are not directly informative about the number of workers who make transitions because of job reallocation. Total turnover does not measure the number of workers involved in labor market transitions during an interval of time, because it double counts job-to-job transitions. In addition, many turnover measures include transitions that are reversed within the sampling interval, but gross job flow measures do not include establishment-level employment changes that are reversed within the interval.

\section{A Summary of Relationships Among the Measures}

We summarize the relationships among the various measures in a few declarative statements:

A. Total turnover equals the number of transitions; i.e., the sum of separations and accessions.

B. Worker reallocation equals the number of workers who make transitions.

C. Job reallocation equals job creation plus job destruction.

D. Job reallocation is an upper bound on the number of workers who participate in transitions that occur because of changes in the location of employment opportunities.

E. Minimum worker reallocation, the maximum of creation and destruction, is a lower bound on the number of workers who participate in transitions that occur because of changes in the location of employment opportunities.

F. Job reallocation is a lower bound on the number of worker transitions that occur because of changes in the location of employment opportunities.

G. Total turnover minus worker reallocation is an upper bound on the number of job-tojob transitions.

We can strengthen $F$ and $G$ to statements involving equalities, if we ignore or delete separations and accessions that are reversed within the sampling interval. 


\section{Sources of Data on Worker and Job Flows}

\section{A. CPS Gross Worker Flows}

Many studies use gross worker flows tabulated from Current Population Survey (CPS) data on labor market status (employed, unemployed, or not in the labor force). ${ }^{6}$ The gross worker flows are tabulated from matched monthly household surveys by counting persons who change labor market status between survey dates. These worker flow statistics are based on a comprehensive, national probability sample and are available at high frequency for a long time span (beginning in 1948), two attractive features of the data.

Unfortunately, CPS-based statistics on gross worker flows suffer from important measurement-related problems. The misclassification of individual employment status generates large spurious gross flows between states. This problem is most serious for transitions between unemployment and out of the labor force, but it is also important for part-time, temporary workers and workers on temporary layoff awaiting recall. Missing observations that are correlated with labor market status present another problem. Several studies (e.g., Abowd and Zellner (1985) and Poterba and Summers (1986)) develop adjustments to the published data for classification and other measurement error problems. Adjustments for classification error are based upon information contained in CPS reinterview surveys. Missing observations are allocated to labor market states by matching the time series behavior of CPS data on stocks with the changes in stocks implied by the measured gross flows.

In addition to measurement problems, the data have other important limitations as well. First, the published CPS gross flows data contain limited information on worker characteristics and the reasons for worker flows. Second, the rotating nature of the CPS panel makes it impossible to follow individuals for more than four consecutive observations at monthly intervals or two consecutive observations at twelve-month intervals. This aspect of the CPS sampling scheme precludes analyis of longer term worker mobility dynamics of the sort that can be carried out with other, smaller panel data sets (see, for example, Loungani and Rogerson, 1989). Third, the CPS has virtually no information on employer characteristics. Finally, it is impossible to measure direct job-to-job transitions.

${ }^{6}$ See, e.g., Clark and Summers (1979), Abowd and Zellner (1985), Poterba and Summers (1986), Blanchard and Diamond (1989, 1990), Davis and Haltiwanger (1992), Davis, Haltiwanger and Schuh (1995). 


\section{B. Unemployment Insurance Administrative Data}

Administrative data on individual worker and firm histories maintained by the unemployment insurance system have been used to measure both worker flows and job flows. Some studies (e.g., Leonard (1987) and Troske (1993)) use the administrative data on firms in particular states to measure gross job flows. More recently, Anderson and Meyer (1994) measure both worker and job flows using the Continuous Worker Benefit History (CWBH) data base, which draws upon UI administrative data on individual workers. The CWBH includes information on firm size and other employer characteristics in the individual worker records. In a similar fashion, Lane, Isaac and Stevens (1993) have linked individual worker records with firm records for the state of Maryland to measure gross worker and job flows.

Using the UI administrative data has many advantages. In principle, the data provide information on all workers and all firms participating in the UI system. Thus, these data offer wide coverage of the business and worker populations. Most importantly, the UI data offer the great advantage of being able to simultaneously measure gross worker flows and gross job flows, and to link the two types of flows at the level of individual employers.

These data also present difficulties and limitations. First, the data on individual workers and employers are not in the public domain, although several researchers have obtained data for particular states through various licensing arrangements. Second, the UI administrative records are maintained by the individual states, which leads to differences among states in the content and structure of the raw data files. Third, because the employer identifier in the UI files can change as a result of corporate restructuring or a change in a firm's reporting practices, there are problems in creating longitudinal employer histories. As a related point, the UI reporting unit may represent an entire firm, part of a firm (e.g., all activity within a particular industry in the state or county), or an individual establishment. In some cases, firms can and do alter the level of aggregation at which they report information to the UI offices. The severity and exact nature of these problems vary among states.

The BLS has been working to overcome such longitudinal and cross-sectional linkage problems, in part by encouraging states to assign unique identification numbers for continuing establishments and firms. While considerable progress has been made in these efforts (see, e.g., Armington (1994)), formidable problems remain, especially for the most complex, multi-unit firms. Such firms are few in number, but they account for much employment. Armington (1994) classifies 47 thousand firms as being the most complex in the 
sense that they consist of multiple legal entities and multiple establishments. In aggregate, these firms employ 37 million workers.

One approach to longitudinal linkage problems in UI data relies upon the Federal Employer Identification Number (FEIN), which typically occupies a field on firm-level UI records. Unfortunately, FEIN identifiers suffer from many of the same problems as the UI account numbers. That is, FEINs change with changes in corporate structure. Further, firms can and do have multiple FEINs (both within and between states). Based upon tabulations from the Bureau of the Census's Standard Statistical Establishment List (SSEL) and Company Organization Survey, among firms with more than one location, there are approximately 1.8 million establishments, 300,000 unique FEINs, and 200,000 firms.

In principle, these problems can be overcome by improvements in processing and standardization among states. As we discuss further in section VII, serious efforts are underway to achieve this goal. At this juncture, one should keep two points in mind about existing gross flow studies based on UI administrative data. First, to the extent that longitudinal linkage problems are present, UI-based data overstate the magnitude of gross job flows and, perhaps, distort their timing. The seriousness of this problem varies among the states and has probably diminished over time, although we are unaware of studies that carefully quantify the extent or pattern of this source of measurement error. Second, job creation and destruction statistics constructed from UI data do not reflect purely establishment-level or firm-level employment changes, but a mixture of the two. Again, we are unaware of studies that carefully address this issue; hence, we cannot assess the magnitude of potential mismeasurement.

\section{BLS Manufacturing Turnover Data (MTD)}

The BLS manufacturing turnover data (MTD) was once a major source of information on worker and job flows. Based upon a monthly survey of manufacturing employers, this survey yielded monthly rates of accessions and separations including a decomposition of accessions into new hires, recalls and other accessions and a decomposition of separations into layoffs, quits and other separations. The data are available from 1930 through 1981. The survey was terminated in 1981, apparently because of budgetary pressures and perceived problems with the survey.

These data have been a key source of information on job and worker flows for important studies by Woytinsky (1942), Lilien (1980), Akerlof, Rose and Yellen (1988), Blanchard and Diamond $(1989,1990)$ and others. Despite the termination of the MTD survey, the data remain an important research tool, because they allow time series analysis of total worker 
turnover and its components. Blanchard and Diamond (1990) develop a methodology for using these series to estimate and study the cyclical behavior of job creation and job destruction. Below, we apply their methodology to the MTD to characterize the relationship between total turnover and job reallocation over the 1930-1981 period.

While the MTD data are valuable and informative, they have important limitations. First, they are restricted to manufacturing. Second, the survey was voluntary, and the sample over-represented large manufacturing employers. Third, the MTD survey did not produce a longitudinal file of individual employers, and, as a consequence, the data do not provide information about the persistence of the establishment-level employment movements that underlie the aggregated turnover statistics. Finally, and quite importantly at this point, the data terminate in 1981.

\section{Unemployment Flows Based on CPS Incidence and Duration Data}

Many studies use CPS data on the incidence and duration of unemployment to measure flows into and out of unemployment. ${ }^{7}$ Since the survey is conducted monthly, the flow into unemployment can be measured as the number of individuals who report an unemployment spell that has been ongoing for less than five weeks. The flow out of unemployment can be measured as the number of unemployed persons in the previous month minus the number of currently unemployed persons who report an unemployment duration of greater than five weeks.

This method has some advantages over the CPS gross worker flows data described above. The duration-based method generates unemployment flows that correspond to movements in the official unemployment rate, because it uses the entire CPS sample. In addition, the duration-based method permits easy cross tabulation of unemployment flows with individual demographic characteristics and reason for unemployemnt (temporary layoff, permanent layoff, quit or entrant). In principle, one could construct the same cross tabulations in the CPS gross worker flow data, but detailed tabulations are unavailable in the published data, and their construction requires longitudinally linking individual-level data across monthly surveys.

There are also important problems and limitations associated with the duration-based measures of unemployment flows. Imperfect recall and other sources of error in the reported duration of ongoing unemployment spells cause mismeasurement of flows into and out of unemployment. Another issue arises when using data on the classification of unemployment

${ }^{7}$ See, e.g., Davis (1987), Darby, Haltiwanger and Plant $(1985,1986)$, Murphy and Topel (1987), Juhn, Murphy and Topel (1991), and Davis, Haltiwanger, and Schuh (1995). 
by reason. These data reflect responses to questions about prospects for recall during an ongoing unemployment spell. As emphasized by Katz and Meyer (1990), it is important to distinguish between ex ante temporary layoffs (worker expects to be recalled at the time of layoff) and ex post temporary layoffs (worker is recalled). The CPS-based data on unemployment by reason provide neither purely ex ante nor purely ex post measures of temporary layoff unemployment. As a consequence, changes over time in the CPS measure of workers on temporary layoff partly reflect variations in the recall expectations of individual workers over the course of ongoing unemployment spells.

It is natural to ask how duration-based measures of unemployment flows compare to measures that rely on counting changes in employment status in longitudinally linked CPS files. Davis, Haltiwanger and Schuh (1995, chapter 6) shed some light on this matter by plotting quarterly data on unemployment inflows and outflows from 1968 to 1986 based on both measurement methods. For the latter method, they use the Abowd-Zellner adjusted gross worker flows data. The duration-based measures show a smaller variance over time and unemployment flow rates that are typically $10-20 \%$ higher than correspoding rates in the Abowd-Zellner data. The simple correlation between the two measures of unemployment inflow (outflow) rates is .92 (.93). Both sets of unemployment flow measures show pronounced seasonality.

\section{E. Dun and Bradstreet Data}

Many early studies of job creation and job destruction are based on the the Dun and Bradstreet Market Identifier (DMI) files. ${ }^{8}$ In principle, the DMI file represents a longitudinal database on individual employers that can be used to measure job creation and destruction on an annual basis for virtually all sectors of the U.S. economy. Unfortunately, while the Dun and Bradstreet data base has many impressive attributes and represents an unparalleled source of information for many commercial purposes, it is not designed or maintained to maximize its usefulness as a tool for statistical analysis of job creation and job destruction. Numerous studies have highlighted severe problems with the DMI files as a tool for measuring job creation and destruction or business births and deaths. ${ }^{9}$

For the purpose of investigating the job-creation process, the DMI files suffer from two key problems. First, there is an enormous discrepancy between U.S. total employment

${ }^{8}$ See, e.g., Birch (1979, 1987), Small Business Administration (numerous years).

${ }^{9}$ See Armington and Odle (1982), Birch and MacCracken (1983), Birley (1984), Howland (1988, chapter 2), Evans (1987), Aldrich et al (1988), and the Small Business Administration $(1983,1987)$. 
as tabulated from the DMI files and the corresponding employment figures produced by the Bureau of Labor Statistics (BLS) or the Bureau of the Census. In 1986, for example, total employment tabulated from the DMI files exceeds the corresponding BLS and Census figures by nine million persons. ${ }^{10}$ In an economy with roughly 110 million employees, a discrepancy of this magnitude raises serious doubts about the accuracy of any statistical portrait generated from the DMI files.

Second, the DMI files do not accurately track business births and deaths or other important employment events. The U.S. General Accounting Office (GAO) has analyzed the accuracy of the DMI files in accounting for mass layoffs, with particular emphasis on layoffs due to plant closures. The Small Business Administration provided the GAO with a sample of mass layoffs and plant closures from the DMI files for the 1982-84 period. ${ }^{11}$ The GAO study found that 81 percent of the mass layoff events in the DMI files were mistakenly identified. In reality, these 81 percent represented some other event, such as a change in ownership structure, not a mass layoff or plant closure.

The DMI files also inaccurately identify plant births. A study by Birley (1984) compares three alternative sources of data for identifying new firms: the DMI file, the ES-202 data generated from administrative records maintained by state unemployment insurance agencies, and the telephone directory. She finds that the DMI files failed to identify 96 percent of the new firms found in the ES-202 data. Using a similar methodology, Aldrich et al. (1988) find that the DMI files missed 95 percent of apparently new businesses in the ES-202 data and 97 percent of those in the telephone directory.

In short, previous research indicates that the DMI files are unsuitable for generating accurate job creation and destruction figures. Identifying plant births and deaths and tracking businesses over time is most difficult in the case of small employers. ${ }^{12}$

\section{F. Longitudinal Research Database}

The Longitudinal Research Datafile (LRD) housed at the Center for Economic Studies at the Bureau of the Census has been the source of numerous recent studies of gross job

${ }^{10}$ See page 514 in the Bureau of the Census (1986).

${ }^{11}$ The GAO defined a mass layoff as the dismissal of at least 20 percent of a plant's permanent work force.

${ }^{12}$ Since it is particularly ill-suited for the study of small employers, it is ironic that the DMI files have been the source of many of the claims of the job creating prowess of small businesses. See Davis, Haltiwanger and Schuh $(1994,1995)$ for further discussion of these issues. 
flows. ${ }^{13}$ The LRD links plant-level data for the Census of Manufactures (CM) and Annual Survey of Manufactures (ASM) for the period 1963-91. The LRD contains a wealth of information that permits construction of annual and quarterly measures of job creation and destruction for the U.S. manufacturing sector cross tabulated by a variety of sectoral and plant characteristics.

There are several key advantages of the LRD relative to other datasets that have been used to measure gross job flows. Important features of the LRD include the comprehensive scope of its sampling frame for a major sector of the U.S. economy, large probability-based samples that minimize sampling error, the incorporation of births into ongoing panels, a careful distinction between firms and establishments, and a careful distinction between ownership transfers and the birth and death of establishments. Through its economic censuses and the Company Organization Survey (COS), the Bureau of the Census assigns individual establishments unique, time-invariant identifiers that enable accurate tracking of the activity at individual establishments over an extended period of time.

Another key advantage of the LRD is that the ASM (and other Census Bureau surveys that can be linked to the ASM) contains a wealth of information about the characteristics of plants and firms including industry, location, size, age, capital intensity, energy intensity, productivity and wages. These employer characteristics can be cross tabulated with measures of gross job flows. Thus, the LRD can be used to provide a wide range of information about the characteristics of the employers that create and destroy jobs.

The LRD also has important limitations. Like the UI based datasets, LRD data are not in the public domain. Currently, use is restricted to studies conducted at the Center for Economic Studies in Suitland, Maryland or at the newly opened Research Data Center in the Census Regional Office in Boston. Second, the data are currently restricted to manufacturing establishments. (As discussed below in section VI, the LRD could be extended to non-manufacturing sectors.) Third, the LRD contains very limited information about workers and worker characteristics. Thus, for example, the LRD does not permit simultaneous measurement of worker and job flows.

${ }^{13}$ See, e.g., Dunne, Roberts and Samuelson (1989), Davis and Haltiwanger (1990, 1992, 1994) and Davis, Haltiwanger and Schuh (1995). Chapter 1 and the Technical Appendix in Davis, Haltiwanger and Schuh (1995) describe the LRD in detail. 


\section{An Overview of What We Know about Gross Worker and Job Flows}

\section{A. Magnitudes}

Table 1 presents estimated average rates of total turnover, gross worker reallocation, gross job reallocation, and minimum worker reallocation. The various estimates draw on different datasets, different sectors, different states and different time periods, so that considerable care must be used in comparing and interpreting the results. All reported rates in Table 1 are measured as percentages of employment. Annual rates reflect changes over twelve-month intervals, while quarterly rates mostly reflect changes over three-month intervals. ${ }^{14}$ Since the MTD includes no direct measures of job creation and destruction, we follow Blanchard and Diamond (1990) and estimate creation and destruction rates from information on separations and accessions. ${ }^{15}$

The annual worker reallocation measure in Table 1 is drawn from Davis and Haltiwanger (1992). ${ }^{16}$ We constructed this measure using two different pieces of information available from the CPS. First, Hall (1982) reports that 28.2 percent of employment in 1978 represents workers with job tenure of 12 months or less. Second, our tabulations of March-March matched CPS files in Davis and Haltiwanger (1992) find that the number of currently jobless persons who were employed 12 months earlier averages 8.6 percent of employment over the 1968-87 period. Summing these two pieces, the total number of persons who currently have a different job or employment status than they had twelve months earlier equals 36.8 percent of employment.

Several measures of total turnover are available on a quarterly basis. Anderson and Meyer (1994) report two different measures constructed from the CWBH. Their "total" measure of quarterly turnover includes workers who were temporarily laid off and recalled within the same quarter, if they can detect such transitions from the payment of unemployment benefits. As such, their measure of quarterly total turnover includes some layoff-recall events that transpire within the quarter. This feature of their total measure complicates comparisons to worker and job flow measures based on changes between discrete points in time. However, Anderson and Meyer also report a "permanent" turnover

${ }^{14}$ The quarterly MTD figures are cumulated from monthly rates. The CWBH figures designated "total" include employment transitions that are reversed within the quarter, as discussed below.

${ }^{15}$ We describe the methodology in subsection $\mathrm{C}$ below.

${ }^{16}$ Table 2 below presents decompositions of quarterly worker reallocation. However, the measures of worker reallocation used for that purpose are obtained by adjusting total turnover figures for direct job-to-job transitions. 
measure that excludes turnover associated with layoff spells that end in recall. Since their definition of temporary turnover includes layoff spells that end in recall within the quarter and some layoff-recall spells that overlap more than one quarterly interval, their permanent turnover measure omits some turnover events that are included in measures from, say, the Marlyand UI data. Nonetheless, the permanent total turnover estimates from Anderson and Meyer more closely correspond to the total turnover estimates from Lane, Isaac and Stevens (1993). This similarity suggests that much of the temporary turnover measured by Anderson and Meyer actually occurs within the quarter. ${ }^{17}$

In any case, total turnover is quite large even when temporary turnover is excluded. According to Table 1, total turnover amounts to about $39 \%$ of employment per quarter, taking the simple mean of the UI-MD and (permanent) CWBH rates for the private sector. Total turnover rates are lower in manufacturing than in the rest of the economy. Using this total turnover figure, a crude estimate of quarterly worker reallocation can be generated by considering the evidence on direct job-to-job transitions in Akerlof, Rose and Yellen (1988) and Blanchard and Diamond (1990). They estimate that between $30 \%$ and $50 \%$ of all separations (and accessions) are associated with direct job-to-job movements. Taking the midpoint of this range, $40 \%$ of total turnover reflects direct job-to-job transitions, which in turn implies that the total turnover rate of $33 \%$ translates into a worker reallocation rate of about $26 \% .^{18}$ That is, roughly one worker in four experiences a change in employer or employment status each quarter. By comparing the annual and quarterly worker reallocation figures, it is clear that many workers experience repeated transitions during the year or transitions that are reversed within the year.

The third panel of Table 1 reports estimates of the job reallocation component of worker flows. Annual job reallocation rates range from $20 \%$ to $30 \%$, and quarterly rates range from $10 \%$ to $19 \%$. The manufacturing sector appears to have lower rates of job reallocation than other sectors, but the differences are not dramatic. In this regard, there is less variation between manufacturing and nonmanufacturing in job reallocation rates than in total turnover rates. It follows that worker reallocation activity for reasons other

${ }^{17}$ Aside from differences in measurement procedures, differences in sample selection criteria between the two studies make us reluctant to give too much weight to this sort of comparison.

${ }^{18}$ We arrive at this figure by calculating $.33[1-(1 / 2)(.40)]=.264$. This calculation adjusts for the fact that each person who experience a job-to-job transition is counted twice in the turnover measure, once as a separation and once as an accession. See section III for further discussion. 
than job creation and destruction plays the dominant role in explaining differences in total turnover rates. Finally, comparing the quarterly job reallocation rates to the annual rates indicates that a significant fraction of the quarterly job reallocation reflects establishmentlevel employment changes that are reversed within the year. We return to this matter below.

\section{B. The Contribution of Job Reallocation to Total Turnover and Worker Reallocation}

Table 2 reports decompositions of total turnover and worker reallocation. The table entries show the percentage of worker transitions and the percentage of workers involved in transitions accounted for by job creation and destruction activity. ${ }^{19}$ Since the LRD does not yield an estimate of total turnover, the LRD/MTD entry in the top panel relies on estimates of total turnover from the MTD. Since the MTD turnover measure includes layoff spells that end in recall within the quarter, the LRD/MTD entry should be interpreted as a lower bound on the percentage of worker transitions in the manufacturing sector that occur because of shifts in the location of employment opportunities (i.e., because of job reallocation activity).

Depending on the data source and sectoral coverage, job reallocation accounts for $35-46 \%$ or more of quarterly total turnover. Although job reallocation rates tend to be lower than average in manufacturing, job reallocation accounts for a higher fraction of total turnover in manufacturing. Thus, as we inferred above, the other forces driving total turnover play a smaller role in the manufacturing sector. ${ }^{20}$

Our decomposition of worker reallocation takes into account the fact that job reallocation represents an upper bound on the number of workers induced by job reallocation.

${ }^{19}$ Table 2 uses Anderson and Meyer's "permanent" total turnover measure, because it is more suitable for comparison with job reallocation statistics based on establishment-level employment changes between two discrete points in time.

${ }^{20}$ Anderson and Meyer (1994) draw a different inference when they use their estimate of total turnover including temporary turnover. Temporary turnover as they define it is disproportionately important in manufacturing. Accordingly, they find that permanent job reallocation accounts for a smaller fraction of total turnover (including temporary turnover) in manufacturing than in other sectors. We find it somewhat difficult to interpret this calculation when it is based on job and worker transitions measured under different sampling procedures. That is, the job reallocation estimate only reflects changes in employment that occur from one point in time to another three months later but their estimate of total turnover includes temporary transitions that reverse themselves within the three-month interval. 
Thus, both the upper bound and lower bound decompositions described in section III are reported. For the annual decompositions, all reported estimates are based on the CPS figure for worker reallocation. For the quarterly decompositions, the reported estimates are based on constructing worker reallocation estimates from the total turnover figures under the assumption that $40 \%$ of all separations and accessions reflect direct job-to-job transitions.

The various datasets yield a consistent picture of the contribution of job reallocation to worker reallocation. The lower bound estimates are all around one third. The upper bound estimates are between one half and two thirds. Simply put, job reallocation accounts for between one third and two thirds of total worker reallocation.

Two observations provide further perspective on the magnitude of job reallocation's contribution to worker reallocation. First, the preceding calculation neglects secondary waves of worker reallocation initiated by job creation and destruction. For example, a person who quits an old job in favor of a newly created job potentially creates a chain of further quits as other workers reshuffle across the set of available job openings. It follows that the direct plus indirect contribution of job reallocation to worker reallocation exceeds the one-third to two-thirds figure derived above. ${ }^{21}$

Second, a certain amount of worker reallocation inevitably arises from life-cycle considerations as old workers retire and young workers enter the work force. If the typical person works 45 years, then retirement and initial labor force entry directly cause transitions between employment and nonemployment equal to about 4.4 percent of the work force in a typical year. It follows from our figure for annual worker reallocation that simple life-cycle effects account for roughly 12 percent of annual worker reallocation. After accounting for job reallocation and life-cycle effects, the residual amount of worker reallocation equals 13.0 percent to 20.7 percent of employment, or 35 percent to 56 percent of annual worker reallocation (using the LRD estimates of job reallocation). This component of worker reallocation reflects temporary exits from the work force and the sorting and resorting of workers across existing jobs for a variety of reasons. Thus, according to ${ }^{21}$ Hall (1995) pursues the implications of this idea for unemployment rate dynamics over the business cycle. He argues that the burst of permanent job destruction at the onset of recessions begets further waves of accessions and separations, since workers whose jobs are destroyed seek new matches, and new matches are subject to higher termination rates than the typical existing match. He presents supporting evidence that the observed persistence in unemployment rate dynamics is closely linked to the slow rebuilding of employment relationships after the sharp episodes of primary job loss at the onset of recessions. 
our estimates, these supply-side reasons for worker reallocation are neither more nor less important than shifts over time in the locational distribution of job opportunities.

\section{Cyclicality}

In this subsection, we briefly characterize the cyclical behavior of job creation, job destruction and total turnover. We also decompose the cyclical variation in total turnover into a component due to job reallocation and a component due to other factors. We focus on the cyclicality of total turnover rather than worker reallocation, because the BLS manufacturing turnover data (MTD) provide high frequency observations on total turnover for an extended period of time. Comparable time series data on U.S. worker reallocation rates are not available.

Figure 1 depicts total turnover and net employment growth for the U.S. manufacturing sector from 1930:1 to 1981:1. ${ }^{22}$ Total turnover was higher in the 1930s than in the post WWII period, but turnover was even higher during WWII. The correlation between the rates of total turnover and net employment growth equals 0.31 over the sample period, but the cyclical relationship between these two variables does not appear stable over time, an issue we address further below.

As we noted above, the BLS manufacturing turnover data do not yield direct estimates of job creation and destruction. The MTD-based figure for job reallocation that appears in Table 1 relies on a procedure suggested by Blanchard and Diamond (1990). Their methodology requires an estimate for the fraction of quits that are replaced. Given such an estimate, one computes gross job destruction as the sum of layoffs and ( 1 minus the quit replacement rate) times the number of quits. One computes gross job destruction as new hires plus recalls minus the quit replacement rate times the number of quits. ${ }^{23}$

${ }^{22}$ MTD accession and separation data exhibit pronounced seasonality, and the nature of the seasonality varies over time. Thus, following Blanchard and Diamond (1990), we used the Census X11 seasonal adjustment procedure on these series to allow for time variation in the nature of the seasonality. To aid in the comparison of the job creation and destruction estimates from the MTD and the LRD, we also seasonally adjusted the LRD-based figures for job creation and destruction using the X11 procedure for the analysis in this section. ${ }^{23}$ Unlike Blanchard and Diamond, we do not make an adjustment for changes in the number of vacancies in our measure of job creation. Instead, as in most other studies, we define job creation as the creation of newly filled employment positions. In contrast, Blanchard and Diamond (1990) attempt to measure the creation of new employment positions, whether filled or not. Elsewhere, we have examined the behavior of job creation with the vacancy 
Based on a one-time BLS survey in 1972, Blanchard and Diamond assume that $85 \%$ of quits are replaced. While this estimate seems reasonable, no direct evidence on time variation in the quit replacement rate is available. Lacking such evidence, we assume a constant $85 \%$ quit replacement rate to generate job creation and destruction rates over the entire MTD sample period. If the true replacement rate is procyclical (a plausible conjecture), the $85 \%$ assumption leads us to understate the increase in job destruction in recessions and to overstate the increase in job creation in booms. It also leads us to understate the relative amplitude of fluctuations in job destruction. ${ }^{24}$

To gauge the accuracy of MTD-based estimates of job creation and destruction rates, Figure 2 reports the quarterly job creation and destruction figures for the 1972-81 period of overlap between the MTD and LRD. Aside from an incorrect assumption about the quit replacement rate, three other factors lead to differences between LRD-based and MTD-based figures for job creation and destruction. First, the quarterly LRD estimates reflect changes over three-month intervals in point-in-time measures of employment levels, whereas the MTD figures reflect cumulative monthly flows over the quarter. Second, the MTD figures include temporary layoff spells that ended in recall within the month. Third, the sample frame for the MTD and the LRD differ. The LRD is based on a national probability sample, but the MTD was a voluntary survey that over-represented large establishments.

Despite these differences, the job creation rates and, especially, the job destruction rates computed from the two different data sources exhibit similar levels and similar patterns of time variation. The correlation between the two job creation (destruction) rates is

adjustment over the period 1951-81 (see Davis, Haltiwanger and Schuh (1995) Figure 5.6). The vacancy adjustment does not change the basic properties of the job creation series. ${ }^{24}$ To see these points, assume that the MTD measures layoffs, new hires, recalls and quits without error. Then the true destruction rate is related to the MTD-based measure according to

$$
D=\tilde{D}+(\tilde{\theta}-\theta) Q,
$$

where $\theta$ denotes the true quit replacement rate, $Q$ denotes the quit rate, and a tilde indicates a measured quantity. Likewise, the true and measured creation rates satisfy

$$
C=\tilde{C}+(\tilde{\theta}-\theta) Q .
$$

If we specify a constant value for $\tilde{\theta}$ when the true quit replacement rate is procyclical, the statements in the text about cyclical measurement error follow immediately. 
$0.76(0.95)$. Thus, Figure 2 suggests that we can use the MTD to characterize the behavior of job creation and destruction rates over a long time period that pre-dates the LRD sample period.

The top panel of Figure 3 displays quarterly rates of job creation, job destruction, job reallocation and net employment growth for the 1972-88 period based on the LRD. The middle and bottom panels display MTD-based figures for the 1947-81 and 1930-40 periods. Table 3 reports summary statistics on correlations and time variability for turnover and job flow rates.

As emphasized by Davis and Haltiwanger (1990, 1992), the top panel of Figure 3 and Table 3 show that over the 1970s and 1980s job creation and job destruction are negatively correlated, job destruction varies much more over the cycle than job creation, and job reallocation varies countercyclically. The middle panel of Figure 3 and the statistics in Table 3 indicate that these basic patterns hold for the U.S. manufacturing sector over the entire post WWII period, but the patterns are less pronounced in the earlier period. In particular, Figure 3 makes clear that job creation was more volatile in the 1950 s than in later periods.

The 1930s offer what at first glance appears to be a very different picture. Based on the correlations reported in Table 3 for the 1930s, job creation and job destruction are positively correlated, job creation varies more over the cycle than job destruction, and job reallocation is procyclical. However, careful examination of the lower panel of Figure 3 reveals that these different patterns are largely driven by the extremely sharp rise in job creation in the summer of 1933. Figure 1 makes clear that this quarter yielded by far the highest net employment growth rate over the 1930-81 period. As emphasized by Woytinsky (1942, see especially Diagram VIII on page 48), the remarkably high employment growth rate in the summer of 1933 must be interpreted in the context of the behavior of employment over the previous four years. By the spring of 1933, employment in manufacturing had fallen to $60 \%$ of its 1929 level. The sharp increase in employment in the summer of 1933 brought employment up to slightly more than $70 \%$ of its 1929 level. Employment in manufacturing did not return to its 1929 level until 1937. While this extreme episode can hardly be dismissed, we note that the the recession in 1937-38 exhibits the pattern that became common in the post-WWII period. Namely, the 1937-38 recession exhibits a sharp increase in job destruction that coincides with a comparatively mild decline in job creation.

We now use the MTD measures to decompose the time variation in total turnover into a component due to job reallocation and a component due to other factors. Figure 4 depicts job reallocation, other turnover (measured as the difference between total turnover 
and job reallocation) and net employment growth for the $1947-81$ period. ${ }^{25}$ Table 3 reports correlations involving these series over alternative time periods.

Figure 4 and Table 3 suggest the following chracterization of the cyclical variation in the components of total turnover. Job reallocation is countercyclical: during recessions the economy intensifies the pace at which it reallocates employment positions among establishments. The number of worker transitions induced by job reallocation activity rises during recessions and declines during expansions. In contrast, the number of worker transtitions (between employers and between employment and joblessness) induced by other factors fiuctuates procyclically. In short, these two conceptually distinct components of total turnover exhibit sharply different cyclical behavior. Having drawn this conclusion, we wish to remind the reader that job reallocation provides a lower bound on the number of worker transitions that occur because of changes in the location of employment opportunities. (See section III.) Thus, our inferences about the cyclical variation in the decomposition of total turnover rest on the assumption that the tightness of the bound does not vary too much over the cycle.

Interestingly, job reallocation has become increasingly countercyclical during the post WWII period. In contrast, turnover due to other forces has maintained the same degree of procyclicality over this period. Consequently, total turnover has become less procyclical over the post WWII period and by the 1970s is essentially acyclical (the correlation of total turnover and net employment in the 1970s is 0.03).

\section{More on the Connection Between Job Flows and Worker Flows}

The preceding sections develop several facts about the connection between worker flows and job flows, but they also also leave many gaps in our statistical portrait. This subsection looks at the connection along several dimensions in order to fill in some of the gaps. We examine the persistence and concentration of job flows and the associated implications for worker flows. We also consider the connection between job flows and unemployment flows. ${ }^{26}$

\section{Persistence of Job Flows}

How persistent are the plant-level employment changes that underlie the job creation and destruction figures? The persistence of plant-level employment changes bears directly

${ }^{25}$ Figure 4 focuses attention on the post WWII time period, because we are less comfortable with our constant quit replacement rate assumption over the earlier period.

${ }^{26}$ Davis, Haltiwanger and Schuh (1995) provide a more thorough treatment of these topics. 
on the nature of the worker reallocation associated with job reallocation. To the extent that job creation and destruction represent short-lived employment changes, the changes can be implemented largely through temporary layoffs and recalls. To the extent that plant-level employment changes are persistent, they must be associated with long-term joblessness or worker reallocation across plants.

In thinking about how to measure persistence, we stress that our focus is on the persistence of the typical newly created or newly destroyed job. This focus is distinct from a focus on the persistence of the typical existing job or the persistence of establishment size. In line with our focus, we measure persistence according to the following definitions:

The $N$-period persistence of job creation is the percentage of newly created jobs at time $t$ that remain filled at each subsequent sampling date through time $t+N$.

The $N$-period persistence of job destruction is the percentage of newly destroyed jobs at time $t$ that do not reappear at any subsequent sampling date through time $t+N$.

Table 4 summarizes the persistence properties of job creation and destruction over various horizons based upon the LRD. In the annual data, roughly seven-in-ten newly created jobs survive for at least one year, and roughly eight-in-ten newly destroyed jobs fail to reappear one year later. After two years, the persistence of annual job creation and destruction falls to 54 percent and 74 percent, respectively. The most important aspect of these results is that the annual job creation and destruction figures largely reflect persistent plant-level employment changes.

The quarterly job flow figures show much smaller persistence rates than the annual figures. There are two reasons for this discrepancy. First, transitory plant-level employment movements, including seasonal movements, are much more likely to enter into the calculation of gross job flows over three-month, as opposed to twelve-month, intervals. Second, over any given horizon, there are fewer sampling dates in the annual data than in the quarterly data. Thus, newly destroyed and newly created jobs must meet more stringent criteria in the quarterly data to satisfy the concept of persistence specified in the definitions above.

These remarks also reconcile the high persistence of annual job creation and destruction with some well-known facts about the importance of temporary layoffs in the U.S. manufacturing sector. For example, Lilien (1980, Table III) using the Manufacturing Turnover Data (MTD) estimates that 60-78 percent of all manufacturing layoffs ended in 
recall during the years 1965 to 1976 . He also reports that 92 percent of manufacturing unemployment spells ending in recall last three months or less. Most of these short-duration temporary layoffs are not captured by the estimates of annual job creation and destruction.

\section{Concentration of Job Flows}

What role do plant births and deaths play in the creation and destruction of jobs? More generally, how are job creation and destruction distributed by plant-level employment growth rates? Do job creation and destruction primarily involve mild expansions and contractions spread among a large number of plants, or wrenching and dramatic changes at a few plants? The consequences of job creation and destruction for workers and for the local communities in which they reside depend, in large part, on the answers to these questions.

Based upon the LRD, Figure 5 displays simple pie charts that condense information on the distribution of annual and quarterly job creation and destruction into a small number of growth-rate intervals. Figure 5 reveals that shutdowns account for 29 percent of annual job destruction, while startups account for 16 percent of annual job creation ${ }^{27}$ The message is plain: much job creation and destruction in the manufacturing sector involve dramatic events such as the startup of a new plant or the death of an old plant.

To elaborate upon this point, Figure 5 also shows that two thirds of annual job creation and destruction occur at startups, shutdowns, and continuing plants that expand or contract by at least a quarter of their initial work force. The dramatic, highly-publicized character of much job creation and destruction activity in the manufacturing sector also reflects the concentration of manufacturing employment at large plants. In 1986, the average manufacturing employee worked at a facility that had nearly 1,600 workers (Davis and Haltiwanger, 1991, Figure 4.B) ${ }^{28}$ Thus, manufacturing employment is concentrated at

${ }^{27}$ Shutdowns and startups account for smaller fractions in the quarterly data for two reasons: (1) these events may require more than a single quarter to complete, and (2) transitory plant-level employment movements account for larger fractions of job creation and destruction in the quarterly data, as shown in the preceding sections. These transitory events are unlikely to involve complete plant shutdowns.

${ }^{28}$ Davis (1990) provides summary statistics on the distribution of employees by establishment size for about 20 manufacturing and 60 nonmanufacturing industries that cover the nonfarm private sector of the U.S. economy. These statistics confirm that employment at large establishments is more important in manufacturing industries than in most nonmanufacturing industries. 
large plants, and manufacturing job creation and destruction are concentrated at plants that experience large percentage changes in employment.

These two facts about concentration explain why job creation and destruction at manufacturing plants often have important effects on nearby communities. A dramatic employment reduction at a single large plant can flood the local labor market, which increases the economic hardship that falls upon each job loser.$^{29}$ Conversely, a sharp employment increase at a single plant can induce an inmigration of workers and their families that strains the capacity of the local community to provide certain public and private goods such as schooling, housing, roads and sewers.

The facts on the concentration and persistence of gross job flows also shed light on the connection between job reallocation and worker reallocation. Since only one third of job destruction is accounted for by establishments that shrink by less than 25 percent over the span of a year, the bulk of job destruction cannot be accommodated by normal rates of worker attrition resulting from retirements and quits. In other words, most of the job destruction represents job loss from the point of view of workers. Since annual job creation and destruction primarily reflect persistent establishment-level employment changes, the bulk of annual job creation and destruction cannot be implemented by temporary layoff and recall policies. Hence, most of the job destruction reflects permanent job loss that leads to a change in employer, a long-term unemployment spell, exit from the labor force, or some combination of these events.

\section{The Connection To Unemployment}

Figure 6 provides information about the cyclical variation in unemployment flows and gross job flows. The unemployment flows are based upon the CPS unemployment incidence and duration data, and the job flows are based on the LRD. ${ }^{30}$ These time-series

${ }^{29}$ See, e.g., Carrington (1993).

${ }^{30}$ This figure combines information on CPS-based unemployment flows for the aggregate economy with the LRD-based job creation and destruction measures for the manufacturing sector. The difference in sectoral coverage naturally raises concerns about comparability. On this matter, the correlation between the aggregate unemployment rate and the manufacturing unemployment rate is 0.92 , where the manufacturing unemployment rate equals the number of unemployed persons who previously worked in the manufacturing sector divided by the sum of that number and manufacturing employment. The close relationship between aggregate unemployment and manufacturing unemployment mitigates concerns that arise from using worker and job flow statistics that differ in scope of sectoral coverage. 
patterns show that unemployment inflows account for most of the cyclical variation in unemployment. During recessions, unemployment inflows rise dramatically. Unemployment outflows also rise during recessions, but by less than their counterparts and not until later in a recession.

Figure 6 shows that the connection between job destruction and worker flows is stronger than that between job creation and worker flows. Job destruction and unemployment inflows rise sharply during recessions, and they exhibit a high contemporaneous correlation (0.71). Looking at the other side of the flows, unemployment outflows show only weak positive correlation with job creation (0.16).

The figure illustrates the mirror-image quality of unemployment-flow dynamics and job-flow dynamics. We have already seen that job destruction rises sharply in recessions, whereas job creation displays much more modest variation over the business cycle. In a similar manner, the unemployment inflows rise sharply in recessions. But the component most closely related to job creation - unemployment outflows - changes relatively little over the business cycle.

This picture of a tight connection between job flows and unemployment flows is further enhanced by consideration of the evidence on unemployment flows by reason of unemployment and by demographic characteristics. We do not present a detailed analysis of the evidence here, but findings presented elsewhere suggest the following characterization. ${ }^{31}$ During good times, unemployment is dominated by entrants, quitters, and young people. These workers transit across states of the labor market to accommodate life-cycle entry and exit and normal search for a suitable job match. During recessions, increases in unemployment are dominated by permanent and temporary layoffs as firms restructure their employment positions. These layoffs are accompanied by an increase in the share of unemployment of prime-age workers (especially men), most of whom have considerable work experience and strong attachment to the labor force. ${ }^{32}$

This interpretation of unemployment-rate dynamics offers an interesting parallel to the details of job-flow dynamics documented in Davis, Haltiwanger and Schuh (1995). Job flows in good times are dominated by the creation and destruction of jobs among relatively young and small plants. These younger and smaller plants are, like young workers, trying

${ }^{31}$ Chapter 6 of Davis, Haltiwanger and Schuh (1995) presents an in-depth analysis of the connection between job flows and unemployment by reason and by demographic characteristics.

${ }^{32}$ Young workers also face increased layoffs in recessions. However, unemployment and unemployment inflows of prime-age workers rise disproportionately. 
to determine whether and where they fit into the marketplace. During recessions, older and larger plants experience sharply higher job destruction rates, so that their contribution to the job and worker reallocation process rises. This time of intense job destruction by older and larger plants coincides with the rise in layoff unemployment, especially among prime-age workers. ${ }^{33}$

\section{A Collection of Facts About Worker Flows and Job Flows}

This brief section lists several facts and empirical regularities related to the behavior of U.S. worker flows and job flows. The list offered below simply collects and restates, sans qualifications and caveats, the main empirical results developed in the preceding section. The symbol "(M)" designates facts drawn from data limited to the manufacturing sector.

- Total worker turnover, the sum of accessions and separations, amounts to about one third of employment per quarter.

- Roughly one worker in four experiences a change in employer or employment status (employed versus not employed) each quarter.

- The number of persons who change employer or employment status in a typical year amounts to about $37 \%$ of employment.

- Average annual job reallocation rates (sum of creation and destruction rates) range from $20-30 \%$ of employment depending on industrial sector, region and time period.

- Average quarterly job reallocation rates range from 10-13\% of employment.

- Annual job creation and destruction figures largely reflect persistent plant-level employment changes. For example, roughly seven-in-ten newly created jobs survive for at least one year, and roughly eight-in-ten newly destroyed jobs fail to reappear one year later. (M)

- Job flows are spatially concentrated: Two thirds of annual job creation and destruction occur at startups, shutdowns, and continuing plants that expand or contract by at least a quarter of their initial workforce. Shutdowns alone account for nearly one quarter of job destruction. (M)

- Job reallocation accounts for $35-46 \%$ or more of total turnover (number of worker transitions) in quarterly data.

- The rate of job reallocation is moderately smaller but accounts for a much larger fraction of total turnover in the manufacturing sector.

\footnotetext{
${ }^{33}$ We believe that older plants disproportionately employer older workers, but we know of no direct evidence on this matter.
} 
- Job reallocation accounts for between one third and two thirds of all persons who change employer or employment status over both three-month and twelve-month intervals.

- The simple correlation between quarterly rates of total turnover and net employment growth equals 0.31 over the 1930 to 1980 period, but the cyclical behavior of turnover is not stable over this time period. (M)

- Job creation and destruction are negatively correlated, job destruction varies more over the cycle than job creation, and job reallocation varies countercyclically. These patterns hold for the entire postwar period, but they are less pronounced in the 1950s and 1960s. (M)

- The number of worker transitions induced by job reallocation activity rises during recessions and declines during expansions. (M)

- In contrast, the number of worker transitions induced by other factors fluctuates procyclically. (M)

- Job destruction and unemployment inflows rise sharply during recessions, and they exhibit a high contemporaneous correlation (0.71). Looking at the other side of the flows, unemployment outflows show only a weak positive correlation $(0.16)$ with job creation. (M)

- During expansions, unemployment is dominated by entrants, quitters, and young persons.

- During recessions, increases in unemployment are dominated by permanent and temporary layoffs. These layoffs are accompanied by an increase in the share of unemployment accounted for by prime-age workers (especially men), most of whom exhibit strong attachment to the labor force.

- During expansions, gross job flows are dominated by the creation and destruction of jobs among relatively young and small plants. (M)

- During recessions, older and larger plants experience sharply higher job destruction rates, so that their contribution to the job and worker reallocation process rises. (M)

\section{New Sources of Data on Gross Job and Worker Flows}

In the preceding sections, we have synthesized and summarized much of what we know about the dynamics of worker flows and job flows, drawing on various datasets and studies. While we have learned a great deal about the dynamics of the labor market from existing data, our understanding is clearly incomplete. U.S. statistical agencies are not currently capable of generating timely, comprehensive worker and job flow statistics for 
the U.S. economy. The economic and policy importance of the dynamics of the labor market constitute a prima-facie argument for developing longitudinal business-level and worker-level databases that permit more timely, comprehensive and detailed measures of worker and job flows. This section discusses possible paths toward that objective. ${ }^{34}$

In the ensuing discussion, we limit attention to the potential uses of existing administrative record databases, because they offer an inexpensive means of constructing statistics on gross job and worker flows. Within that constraint, our discussion ranges from general remarks about methods for measuring gross flows to specific remarks about the advantages and disadvantages of particular data sources. The specific remarks serve to delineate reasonable objectives for data construction and to highlight some of the issues that must be confronted in developing longitudinal business-level databases.

\section{A. The Standard Statistical Establishment List}

The Standard Statistical Establishment List (SSEL) merits serious consideration as a comprehensive source of statistics on annual gross job flows. The SSEL is the master establishment list for all businesses with at least one employee in the United States. The Bureau of the Census maintains the SSEL using Internal Revenue Service administrative records and drawing heavily on information contained in the Bureau's annual Company Organization Survey (COS). Currently, the Bureau of the Census uses the SSEL to define the statistical sampling frame for its many economic censuses and surveys of individual businesses. ${ }^{35}$ Initial efforts to construct gross job flow statistics from the SSEL have been underway at the Bureau of the Census for the past two years.

The SSEL offers important advantages as a potential source of job creation and destruction statistics. First, as with the LRD, establishments (i.e., physical locations) constitute the observational units. Second, the SSEL is suitable for tracking individual establishments over time in a way that correctly treats mergers, births and deaths, and transfers of ownership and control. These strengths of the SSEL stem in large part from its reliance on the Company Organization Survey.

The COS provides information about the ownership and operational control of production and nonproduction facilities, information that enables the Census Bureau to distinguish between establishments and enterprises. In the SSEL, as in the LRD, an enterprise is either a single establishment owned and operated by a single-unit firm or the set of

${ }^{34}$ This section draws heavily from Chapter 8 of Davis, Haltiwanger and Schuh (1995).

${ }^{35}$ Bureau of the Census (1979) describes the use of the SSEL as a sampling frame for Census surveys. 
establishments under the ownership and operational control of the same firm. ${ }^{36}$ Thus, the SSEL offers the promise of circumventing the spurious linkage problems that potentially compromise efforts to track individual establishments through time, to distinguish between establishments and enterprises, and to accurately measure gross job flows. ${ }^{37}$ Spurious job flows can arise when longitudinal links are incorrectly broken because of simple processing errors or because of changes in ownership, corporate status, business name or address, or taxpayer employer identification number.

The SSEL contains annual data on employment and payroll plus information on location, industry and establishment age. The SSEL for any given year becomes available in the subsequent year, so that gross job flow statistics by detailed industry, state, local area, establishment and enterprise size, establishment and enterprise wage level, and establishment age could be made available on a yearly basis with a lag of approximately nine to twelve months. In addition, the SSEL could be linked to the many business censuses and surveys conducted by the Bureau of the Census. In this way, it would be feasible to provide gross job flow statistics broken down by a wealth of other establishment and enterprise characteristics including sales, investment, input usage, inventories, international trade involvement, and technology usage.

${ }^{36}$ During inter-censal years the sample frame of the COS is the set of multi-unit companies with at least 50 employees in the previous economic census. Consequently, new establishments born in an inter-censal year and affiliated with establishments classified as single-unit establishments in the previous census will not be properly linked to their parent firm until the subsequent census. Similarly, new establishments affiliated with companies that had fewer than 50 employees in the previous census will not be properly linked to their parent firm until the subsequent census. This feature of the COS does not affect the quality of the longitudinal establishment linkages in the SSEL, but it does affect the quality of the enterprise identifiers. As such, it affects, for example, the ability to track employment growth by enterprise size (as opposed to establishment size). See Bureau of the Census (1979) for further discussion of how the COS is used to maintain the SSEL. ${ }^{37}$ The SSEL contains a variety of establishment and enterprise identifiers (e.g., the Census Bureau identification number, the federal taxpayer identification number, and the permanent plant number (PPN)) that facilitate longitudinal and cross-sectional linkages. Other information in the SSEL such as company and establishment names, street address, and detailed industry and location codes can be used to verify the linkages and enhance their quality. See Bureau of the Census (1979) for a discussion of how the various identifiers in the SSEL are created. 


\section{B. The Bureau of Labor Statistics 202 Dataset}

The Bureau of Labor Statistics (BLS) 202 dataset also merits serious consideration as a comprehensive source of gross job flow statistics for the U.S. economy. This dataset contains quarterly employment and payroll records on all businesses subject to unemployment insurance laws. The 202 dataset serves as the statistical sampling frame for most BLS establishment surveys (Manser, 1994). Thus, the 202 dataset closely parallels the SSEL in scope, content and use as a sample frame. Several researchers have used UI-based data from selected states to create longitudinal files and analyze job flow behavior. ${ }^{38}$

There are two main drawbacks to using UI-based data to measure gross job flows. First, as discussed in section IV, UI reporting units do not correspond precisely to either establishments or enterprises. A UI reporting unit may represent an establishment, an enterprise, a division of an enterprise, one payroll office of an enterprise, or all or some establishments owned by the same firm and located within the same state. In addition, firms can and do change the way in which they report payroll information to UI offices. Because of nonlinearities and experience rating in the UI tax structure, firms may have incentives to change their reporting patterns over time. ${ }^{39} \mathrm{~A}$ second and related drawback to UI-based data arises from the lack of standardization in reporting practices among states. While efforts to achieve greater standardization are ongoing, the absence of full standardization is likely to slow progress in clearly identifying establishments and enterprises, in constructing accurate longitudinal linkages, and in developing operational procedures for accurately measuring and reporting gross job flow statistics. Efforts to address these problems with UI data are currently underway at the BLS (see, e.g., Armington $(1991,1994)$ ).

Two important advantages of the BLS 202 dataset, relative to the SSEL, are its greater timeliness and frequency. Quarterly employment and wage records become available approximately five months after the close of the quarter (Manser, 1994). Thus, quarterly gross job flow statistics computed from 202 data could be released on a quarterly rather than yearly basis and with a shorter time lag than statistics calculated from the SSEL.

\footnotetext{
${ }^{38}$ See Leonard (1987), Troske (1993), Lane, Isaac and Stevens (1993), and Anderson and Meyer (1994).

${ }^{39}$ Many previous users of UI-based data have recognized these problems. Some researchers have used information in the UI files to distinguish ownership transfers from births and deaths. Some researchers have also used taxpayer employer identification numbers in an attempt to construct firm-level data from UI records. Unfortunately, as discussed in section IV, the taxpayer employer identification number does not have a precise or stable mapping to an economic concept of the firm.
} 
As another advantage, UI-based data offer the possibility of generating monthly statistics on gross job flows, either directly from the 202 data or by linking the monthly BLS 790 data to the 202 data. $^{40}$ Thus, in principle UI-based data could be used to generate monthly gross flows on a comprehensive, timely basis broken down by industry and geographic area. For policymakers (e.g., the monetary authorities) and business forecasters who rely heavily on high-frequency, real-time economic indicators, reporting monthly gross job flow statistics with a short lag would be of great interest. Monthly gross job flow data would also be useful in research on business cycles and other topics.

\section{A National Wage Records Database}

A key advantage of UI-based data involves prospects for simultaneously measuring worker and job flows from a longitudinal employer-worker database that links workers to employers. In addition to the employer records that enter into the BLS 202 dataset, the individual states maintain quarterly earnings records for individuals at UI-covered firms to assess eligibility and compute benefit amounts for unemployment insurance claimants. ${ }^{41}$ These records contain information suitable for following individuals over time and for identifying their employers. A current BLS initiative is considering how these records might be combined into a National Wage Records Database (NWRD) that would be useful for measuring job flows, worker flows and related concepts. ${ }^{42}$

Unlike the SSEL and the BLS 202 data, the NWRD offers the prospect of comprehensive statistics on job flows and worker flows. Because individual workers could be linked to individual employers, this database also offers much greater scope for describing and analyzing the connection between worker and job flows. ${ }^{43}$ In addition, a wealth of infor-

${ }^{40}$ The BLS 790 dataset provides monthly employment observations on a sample of establishments covered by the unemployment insurance system. According to Manser (1994), the BLS 202 data also now provides monthly data.

${ }^{41}$ The states also maintain individual-level files that track unemployment insurance claims and benefit payments.

${ }^{42}$ This initiative was the focus of an April 1994 BLS conference held in Washington, D.C. ${ }^{43} \mathrm{As}$ discussed in section IV, two sets of researchers have already used the type of data envisioned for the NWRD to simultaneously measure worker and job flows. See Lane, Isaac and Stevens (1993) and Anderson and Meyer (1994). Both studies expand our knowledge of labor market dynamics, and they demonstrate the feasibility and value of using a UI-based linked employer-worker database as a research tool. 
mation in the many BLS employer surveys could be linked to the NWRD and used to shed additional insight into the behavior of worker flows and job flows. ${ }^{44}$

The NWRD would be constructed from the same data collection system as the BLS 202 data. Consequently, it would be subject to the same cross-sectional and longitudinal linkage problems as the 202 data. Relative to its enormous value as a tool for research and policy analysis, however, these shortcomings of a UI-based longitudinal employer-worker dataset are minor.

\section{Possibilities and practicalities}

The preceding discussion makes clear that administrative data already exist at both the Bureau of the Census and the Bureau of Labor Statistics that could be used to measure gross job flows in a timely, comprehensive and detailed manner. Converting these administrative records into operational longitudinal data files would require considerable effort and resources, but the costs would be small relative to alternative approaches that require major new surveys or other data sources.

The administrative records data at the BLS and Census offer distinct advantages and disadvantages that reflect differences in the history and mission of the two bureaus. Data at the Bureau of the Census offer greater scope for spelling out the connection between job flows and employer characteristics. Data at the Bureau of Labor Statistics offer the prospect of directly linking job flows to worker flows and worker characteristics.

Ideally, data from both bureaus would be combined so as to simultaneously link job flows to employer characteristics, worker flows and worker characteristics. Although the current institutional structure of the statistical bureaus stands in the way of efforts to pool data resources, we strongly advocate cooperative agreements and mechanisms that facilitate the sharing of survey and administrative record data on individual businesses. Such data sharing arrangements would greatly enhance the value of both Census and BLS data as tools for economic research and policy evaluation. By providing each bureau with an alternative business universe, data sharing arrangements would also facilitate the identification of problems with existing statistical sampling frames and, over time, lead to improvements in the accuracy of published statistics. ${ }^{45}$

\footnotetext{
${ }^{44}$ Manser (1994) summarizes the many surveys of labor market behavior carried out by the BLS.

${ }^{45}$ Manser (1994, p.25) also remarks upon the potential benefits of data sharing arrangements between the Census and BLS.
} 


\section{References}

Abowd, John, and Arnold Zellner (1985) "Estimating Gross Labor Force Flows," Journal of Economic and Business Statistics, 3, no. 3, 254-83.

Akerlof, George, Andrew Rose, and Janet Yellen (1988) "Job Switching and Job Satisfaction in the U.S. Labor Market," Brookings Papers on Economic Activity (1988:2), 495-582.

Albaek, Karsten and Bent E. Sorensen (1995) "Worker Flows and Job Flows in Danish Manufacturing, 1980-91," Unpublished.

Aldrich, Howard, Arne Kallenberg, Peter Marsden, and James Cassell (1988) "In Pursuit of Evidence: Five Sampling Procedures for Locating New Businesses," paper prepared for 1988 Babson College Entrepreneurship Conference.

Anderson, Patricia M. and Bruce D. Meyer (1994) "The Nature and Extent of Turnover," Brookings papers on Economic Activity: Microeconomics, 1994.

Armington, Catherine (1991) "Firm Linkage of the 1989 Universe Data Base," Final Report on Department of Labor Contract No. J-9-J-9-0091.

Armington, Catherine (1994) "Proposed Structure and Content for BLS' Longitudinal Establishment and Firm Database," processed.

Armington, Catherine and Marjorie Odle (1982) "Sources of Employment Growth, 197880," unpublished report, The Brookings Institution, Washington, D.C.

Baily, Martin Neil, Eric J. Bartelsman, and John Haltiwanger (1994) "Downsizing and Productivity Growth: Myth or Reality?" NBER Working Paper No. 4741.

Birch, David L. (1979) The Job Generation Process, Cambridge: MIT Program on Neighborhood and Regional Change.

Birch, David L. (1987) Job Creation in America: How Our Smallest Companies Put the Most People to Work, New York: The Free Press.

Birch, David and Susan MacCracken (1983) "The Small Business Share of Job Creation: Lessons Learned from the Use of a Longitudinal File," unpublished report, MIT Program on Neighborhood and Regional Change.

Birley, Susan (1984) "Finding the New Firm," Proceedings of the Academy of Management Meetings, 47:64-68.

Blanchard, Olivier, and Peter Diamond (1989) "The Beveridge Curve," Brookings Papers on Economic Activity (1989:1), 1-60.

Blanchard, Olivier, and Peter Diamond (1990) "The Cyclical Behavior of Gross Flows of Workers in the U.S.," Brookings Papers on Economic Activity (1990:2), 85-155. 
Bureau of the Census (1979) "The Standard Statistical Establishment Program," Bureau of the Census Technical Paper No. 44 (January), report prepared by the Economic Surveys Division.

Bureau of the Census (1986) Statistical Abstract of the United States, Washington, D.C.: U.S. Department of Commerce.

Caballero, Ricardo (1992) "A Fallacy of Composition," American Economic Review, 82, no. $5,1279-92$.

Caballero, Ricardo and Eduardo Engel (1993) "Microeconomic Adjustment Hazards and Aggregate Dynamics," Quarterly Journal of Economics, 108, no. 2, 313-58.

Caballero, Ricardo, Eduardo Engel, and John Haltiwanger (1994) "Aggregate Employment Dynamics: Building from Microeconomic Evidence," processed.

Caballero, Ricardo and Mohamad Hammour (1994a) "The Cleansing Effect of Recessions," forthcoming in American Economic Review.

Caballero, Ricardo and Mohamad Hammour (1994b) "On the Timing and Efficiency of Creative Destruction," NBER Working Paper No. 4768.

Carrington, William J. (1993) "Wage Losses for Displaced Workers," Journal of Human Resources, 28, no. 3, 435-62.

Clark, Kim, and Lawrence Summers (1979) "Labor Market Dynamics and Unemployment: A Reconsideration," Brookings Papers on Economic Activity, (1979:2), 13-60.

Cooper, Russell and John Haltiwanger (1993) "The Aggregate Implications of Machine Replacement: Theory and Evidence," American Economic Review, 83, no. 3, 360-82.

Darby, Michael, John Haltiwanger, and Mark Plant (1985) "Unemployment Rate Dynamics and Persistent Unemployment under Rational Expectations," American Economic Review, 75, no. 4, 614-37.

Darby, Michael, John Haltiwanger, and Mark Plant (1986) "The Ins and Outs of Unemployment: The Ins Win," NBER Working Paper No. 1997.

Davis, Steven J. (1987) "Fluctuations in the Pace of Labor Reallocation," CarnegieRochester Conference Series on Public Policy, 27, 335-402.

Davis, Steve J. (1990) "Size Distribution Statistics from County Business Patterns Data," processed, University of Chicago.

Davis, Steven J. and John Haltiwanger (1990) "Gross Job Creation and Destruction: Microeconomic Evidence and Macroeconomic Implications," NBER Macroeconomics Annual, 5, 123-68. 
Davis, Steve J. and John Haltiwanger (1991) "Wage Dispersion between and within U.S. Manufacturing Plants, 1963-86," Brookings Papers on Economic Activity: Microeconomics, 115-200.

Davis, Steven J. and John Haltiwanger (1992) "Gross Job Creation, Gross Job Destruction, and Employment Reallocation," Quarterly Journal of Economics, 107, no. 3, 819-63.

Davis, Steven J. and John Haltiwanger (1994) "Driving Forces and Employment Fluctuations: New Evidence and Alternative Explanations," processed.

Davis, Steve, John Haltiwanger, and Scott Schuh (1994a) "Small Business and Job Creation: Dissecting the Myth and Reassessing the Facts," in Lewis C. Solmon and Alec R. Levenson, editors, Labor Markets, Employment Policy, and Job Creation. Boulder, Colorado: Westview Press.

Davis, Steve, John Haltiwanger, and Scott Schuh (1994b) "Job Flows, Worker Flows, and Unemployment Over the Business Cycle," processed.

Davis, Steve, John Haltiwanger, and Scott Schuh (1995) Job Creation and Destruction, forthcoming, MIT Press.

Dunne, Timothy, Mark Roberts, and Larry Samuelson (1989) "Plant Turnover and Gross Employment Flows in the U.S. Manufacturing Sector," Journal of Labor Economics, 7 , no. $1,48-71$.

Evans, David (1987) "The Relationship between Firm Growth, Size and Age: Estimates for 100 Manufacturing Industries," Journal of Industrial Economics, 35, no. 4, 567-81.

Hall, Robert E. (1982) "The Importance of Lifetime Jobs in the U.S. Economy," American Economic Review, 72, no. 4, 716-24.

Hall, Robert E. (1995) "Lost Jobs," Brookings Papers on Economic Activity, (forthcoming).

Hamermesh, Daniel S. (1993) Labor Demand, Princeton: Princeton University Press.

Hopenhayn, Hugo and Richard Rogerson (1993) "Job Turnover and Policy Evaluation: A General Equilibrium Analysis," Journal of Political Economy, 101, no. 5, 915-38.

Howland, Marie (1988) Plant Closings and Worker Displacements: The Regional Issues, Kalamazoo: W.E. Upjohn Institute for Employment Research.

Jovanovic, Boyan (1982) "Selection and the Evolution of Industry," it Econometrica, 50, no. 3, 649-70.

Juhn, Chinhui, Kevin M. Murphy and Robert H. Topel (1991) "Why Has the Natural Rate of Unemployment Increased Over Time?" Brookings Papers on Economic Activity (1991:2), 75-142. 
Katz, Lawrence F. and Bruce D. Meyer (1990) "Unemployment Insurance, Recall Expectations, and Unemployment Outcomes," Quarterly Journal of Economics, 105, no. 4, 973-1002.

Lane, Julia, Alan Isaac and David Stevens (1993) "How Do Firms Treat Workers? Worker Turnover at the Firm Level," processed.

Leonard, Jonathan S. (1987) "In the Wrong Place at the Wrong Time: The Extent of Frictional and Structural Unemployment," in Unemployment \& the Structure of Labor Markets, Kevin Lang and J. Leonard eds., New York: Basil Blackwell.

Lilien, David (1980) "The Cyclical Pattern of Temporary Layoffs in United States Manufacturing," Review of Economics and Statistics, 62, no. 1, 24-31.

Loungani, Prakash and Richard Rogerson (1989) "Cyclical Fluctuations and the Sectoral Reallocation of Labor: Evidence from the PSID," Journal of Monetary Economics, 23, 259-273.

Manser, Marilyn E. (1994) "Existing Labor Market Data: Current and Potential Research Uses," Bureau of Labor Statistics, July.

Mortensen, Dale T. (1992) "The Cyclical Behavior of Job and Worker Flows," working paper, Northwestern University.

Mortensen, Dale T. (1994) "Reducing Supply-Side Disincentives to Job Creation, " processed.

Mortensen, Dale T. and Christopher A. Pissarides (1993) "The Cyclical Behavior of Job Creation and Job Destruction," in Labor Demand and Equilibrium Wage Formation, edited by Jan C. Van Ours, Gerard A. Pfann and Geert Ridder. Amsterdam: NorthHolland.

Murphy, Kevin and Robert Topel (1987) "The Evolution of Unemployment in the United States: 1968-1985," NBER Macroeconomics Annual: 1987, 11-58.

Olley, G. Steven and Ariel Pakes (1992) "The Dynamics of Productivity in the Telecommunications Equipment Industry," Center for Economic Studies Working Paper 92-2.

Organization for Economic Cooperation and Development (1994) Employment Outlook.

Poterba, James and Lawrence Summers (1986) "Reporting Errors and Labor Market Dynamics," Econometrica, 54, no. 6, 1319-38.

Sattinger, Michael (1993) "Assignment Models of the Distribution of Earnings," Journal of Economic Literature, 31, no. 2, 831-80.

Small Business Administration (1983, 1987, 1988, 1991) The State of Small Business: A Report of the President, Washington, D.C.: U.S. Government Printing Office. 
Troske, Kenneth (1993),"The Dynamic Adjustment Process of Firm and Exit in Manufacturing and Finance, Insurance, and Real Estate", processed.

Woytinsky, Wladimir S. (1942) Three Aspects of Labor Dynamics, Washington, D.C.: Committee on Social Security, Social Science Council. 
Table 1

Estimated Average Rates of Worker and Job Flows

(As Percentages of Employment)

Worker Reallocation

Dataset (Sector):

CPS (All)

Several (All)

Dataset (Sector):

CWBH (All)-Total

CWBH (Mfg)-Total

CWBH (All)-Permanent

CWBH (Mfg)-Permanent

UI-MD (All)

UI-MD (Mfg)

MTD (Mfg)

Dataset (Sector):

LRD (Mfg)

CWBH (All)-Permanent

CWBH (Mfg)-Permanent

UI-MD (All)

UI-MD (Mfg)

MTD (Mfg)
Annual

36.8

Total Turnover

Annual

Quarterly

43.6

49.3

31.6

26.3

34.3

22.8

20.9

Job Reallocation

Annual

19.4

21.2

21.6
Quarterly

10.7

13.4

12.0

12.0

10.0

11.1

Minimum Worker Reallocation Required to Accomodate Job Reallocation

Dataset (Sector):

LRD (Mfg)

CWBH (All)-Permanent

$\operatorname{MTD}(\mathrm{Mfg})$
Annual

11.7

11.3
Quarterly

6.2

8.1

6.5

Notes: 1. CPS - Based on tabulations from the Current Population Survey reported in Hall (1982) for 1978 and in Davis and Haltiwanger (1992) for the period 1968-87. See the text for details. 2. CWBH - Tabulations from the Continuous Worker and Benefit History files rported in Anderson and Meyer (1994) for the period 1979-83. 3. UI-MD - Tabulations of Unemployment Insurance Administrative Data for the State of Maryland reported in Lane, Isaac and Stevens (1993) for the period 1986-91. 4. LRD - Tabulations from the Longitudinal Research Database reported in Davis, Haltiwanger and Schuh (1995) for the period 1972 to 1988. 5. MTD - Authors' calculations based on Manufacturing Turnover Data for 1972-81. See the text for an explanation of how these data are used to calculate job reallocation figures. 6. See the text for an explanation of how the quarterly worker reallocation rate is calculated. 
Table 2

Decompositions of Total Turnover and Worker Reallocation

\section{Total Turnover (Number of Worker Transitions) Accounted for by Job Reallocation, Percentages}

Dataset (Sector):

Annual

Quarterly

CWBH (All)-Permanent

42

CWBH (Mfg)-Permanent

46

UI-MD (All)

UI-MD ( $\mathrm{Mfg}$ )

35

LRD/MTD (Mfg)

44

53 (lower bound)

Worker Reallocation (Number of Workers Engaged in Transitions) Accounted for by Job Reallocation, Percentages

$\begin{array}{lllll} & \text { Annual } & & \text { Quarterly } \\ & \text { Lower } & \text { Upper } & \text { Lower } & \text { Upper } \\ \text { Dataset (Sector): } & \text { Bound } & \text { Bound } & \text { Bound } & \text { Bound } \\ \text { CWBH (All)-Permanent } & 31 & 58 & 32 & 53 \\ \text { CWBH (Mfg)-Permanent } & & 59 & & 57 \\ \text { UI-MD (All) } & & & & 55 \\ \text { MTD (Mfg) } & 32 & 53 & 37 & 66 \\ \text { LRD (Mfg) } & & & 37 & 66\end{array}$

Notes: 1. See notes to Table 1 for sources. 2. The LRD/MTD-based decomposition of quarterly total turnover uses the MTD figure for total turnover and the LRD figure for job reallocation. 3. All annual decompositions of worker reallocation use the CPSbased figure for worker reallocation reported in Table 1. 4. All quarterly decompostions of worker reallocation are based on assuming that $40 \%$ of all separations are direct job-to-job transitions. This assumption yields an estimate of worker reallocation equal to four-fifths of total turnover. 
Table 3

Cyclical Properties of Gross Flows

\begin{tabular}{|c|c|c|c|c|c|}
\hline & $\begin{array}{l}\text { Correlation } \\
\text { of Creation, } \\
\text { Destruction }\end{array}$ & $\begin{array}{l}\text { Variance } \\
\text { Ratio of } \\
\text { Destruction } \\
\text { to Creation }\end{array}$ & $\begin{array}{l}\text { Correlation } \\
\text { of Net, } \\
\text { Reallocation }\end{array}$ & $\begin{array}{l}\text { Correlation } \\
\text { of Net, } \\
\text { Total } \\
\text { Turnover }\end{array}$ & $\begin{array}{l}\text { Correlation } \\
\text { of Net, } \\
\text { Other } \\
\text { Turnover }\end{array}$ \\
\hline \multicolumn{6}{|c|}{ Dataset (Time Period) } \\
\hline $\begin{array}{l}\text { LRD }(72: 2-88: 4) \\
\text { LRD }(72: 1-81: 4)\end{array}$ & $\begin{array}{l}-.35 \\
-.47\end{array}$ & $\begin{array}{l}2.96 \\
2.73\end{array}$ & $\begin{array}{l}-.52 \\
-.51\end{array}$ & & \\
\hline $\operatorname{MTD}(30: 1-81: 4)$ & .22 & 0.68 & .19 & .31 & .22 \\
\hline MTD (72:1-81:4) & -.43 & 5.27 & -.72 & .03 & .38 \\
\hline $\operatorname{MTD}(47: 1-81: 4)$ & .09 & 1.35 & -.15 & .29 & .40 \\
\hline $\operatorname{MTD}(30: 1-40: 4)$ & -.45 & 0.43 & .44 & .46 & -0.07 \\
\hline
\end{tabular}

Table 4

Average Persistence Rates for Job Creation and Destruction

Annual Measures, 1972-88

Quarterly Measures, 1972:2-1988:4

Horizon

Creation Destruction

Creation

67.8

50.4

2 quarters

1 year

82.3

70.2

73.6

37.7

22.6

Destruction

72.3

58.9

59.2

54.4

73.6

38.4

Note: Tabulations from LRD reported in Davis, Haltiwanger and Schuh (1995). 
Table 5

Cyclical Changes in Unemployment, By Reason (All Workers)

Fraction of Change in

Unemployment Due to:

Temporary Layoffs

Permanent Layoffs

Quits

Entrants

Change in Unemployment:

Temporary Layoffs

Permanent Layoffs

Quits

Entrants

Change in Unemployment:

Temporary Layoffs

Permanent Layoffs

Quits

Entrants

Change in Unemployment:

Temporary Layoffs

Permanent Layoffs

Quits

Entrants

Change in Unemployment:

Temporary Layoffs

Permanent Layoffs

Quits

Entrants

Change in Unemployment:
Trough

to Peak

Average, 1970:11-1992:12

0.58

0.33

$-0.06$

0.14

$-2.7$

1970:11-1975:3

(70:11-73:11)

0.50

0.29

$-0.18$

0.38

$-1.0$

1975:3-1980:7

(75:3-80:1)

0.44

0.42

0.03

0.11

$-2.3$

1980:7-1982:11

(80:7-81:7)

1.11

0.08

$-0.05$

0.14

$-0.5$

1982:11-1991:3

(82:11-90:7)

0.28

0.54

$-0.03$

0.21

$-4.9$
Peak to Trough

0.32

0.46

0.02

0.21

2.8

(73:11-75:3)

0.44

0.40

0.00

0.16

4.6

(80:1-80:7)

0.19

0.26

0.05

0.50

1.0

(81:7-82:11)

0.32

0.65

$-0.05$

0.09

3.0

(90:7-91:3)

0.46

0.67

$-0.02$

$-0.11$

1.6

Note: Tabulations from CPS reported in Davis, Haltiwanger and Schuh (1995). 
Figure 1

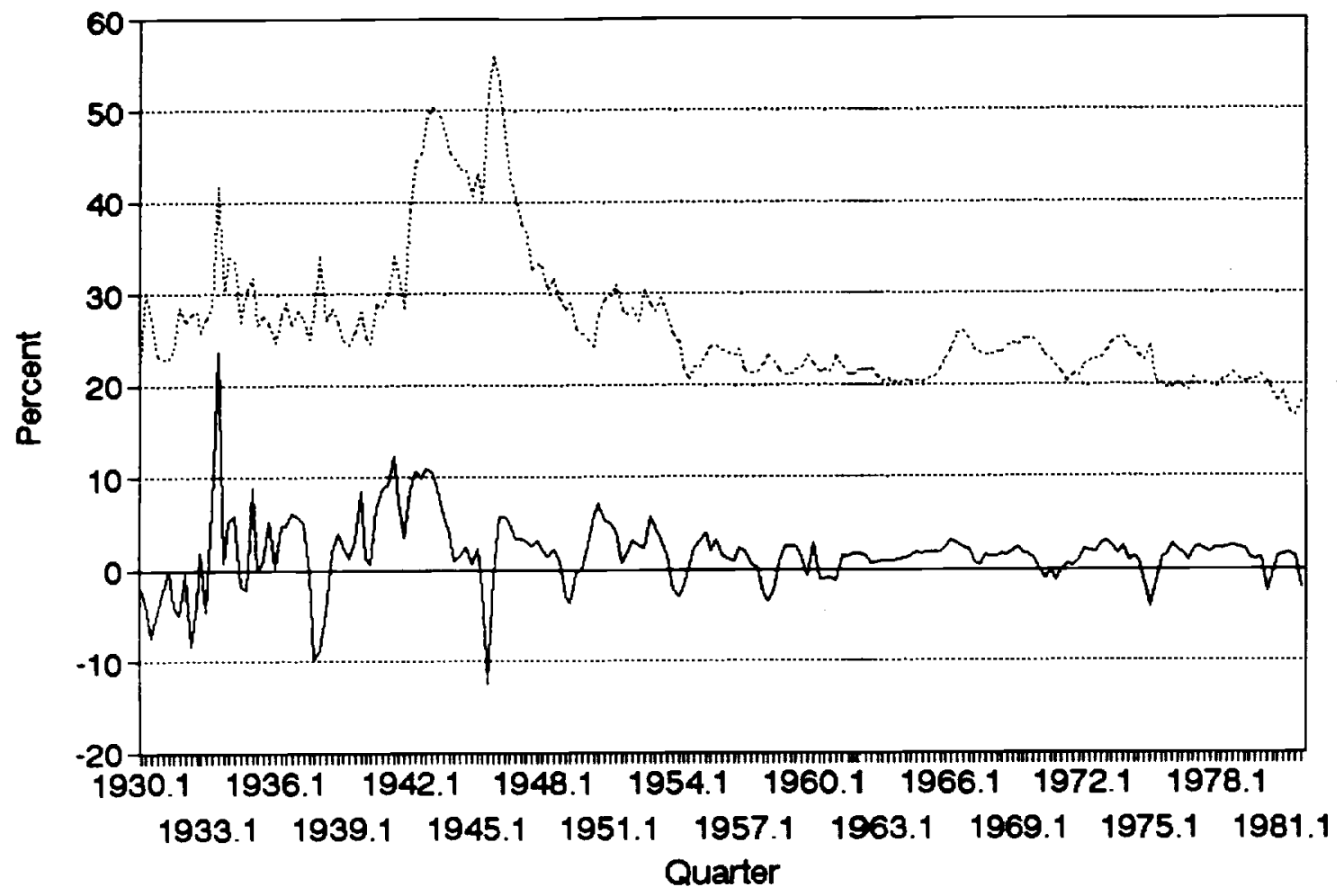

NET EMP GROWTH …… TOTAL TURNOVER 
Floure 20

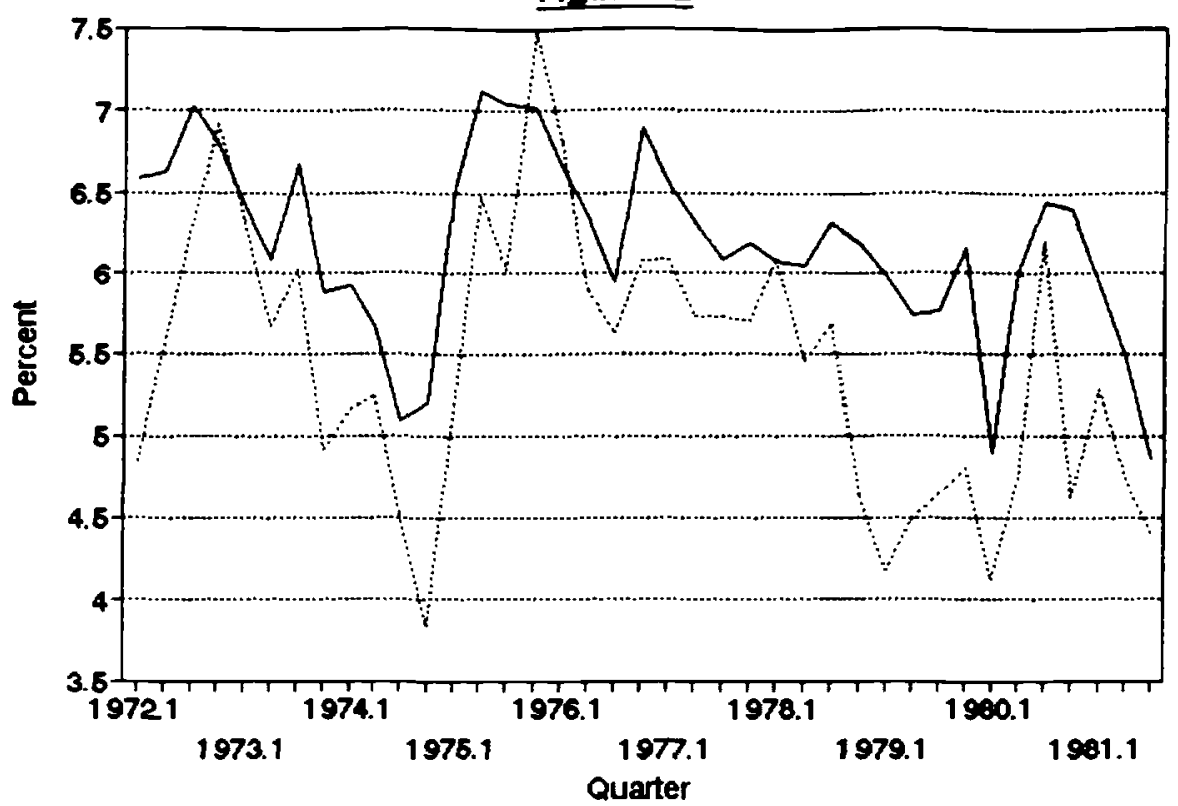

$$
\text { - BLS - CREATION ……' LRD -CREATION }
$$

Flgure 2b

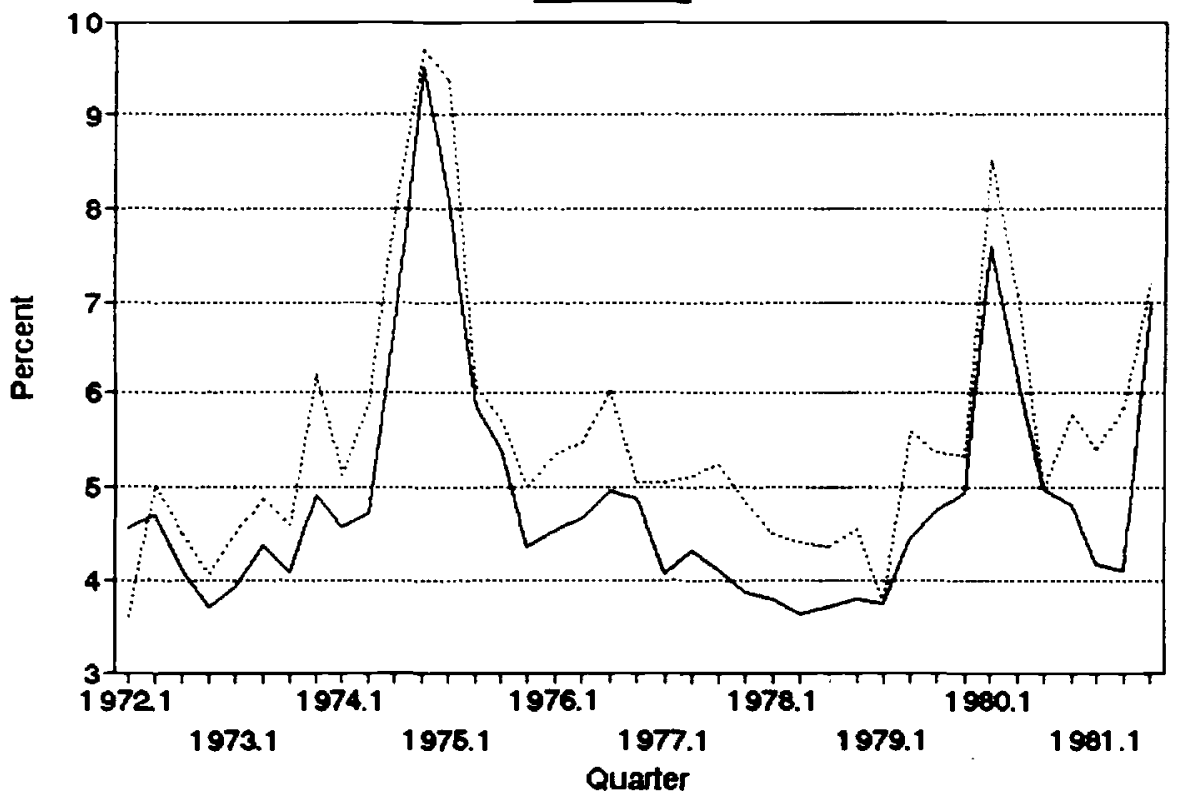

$$
\text { - BLS - DESTRUCTION ……. LRD - DESTRUCTON }
$$




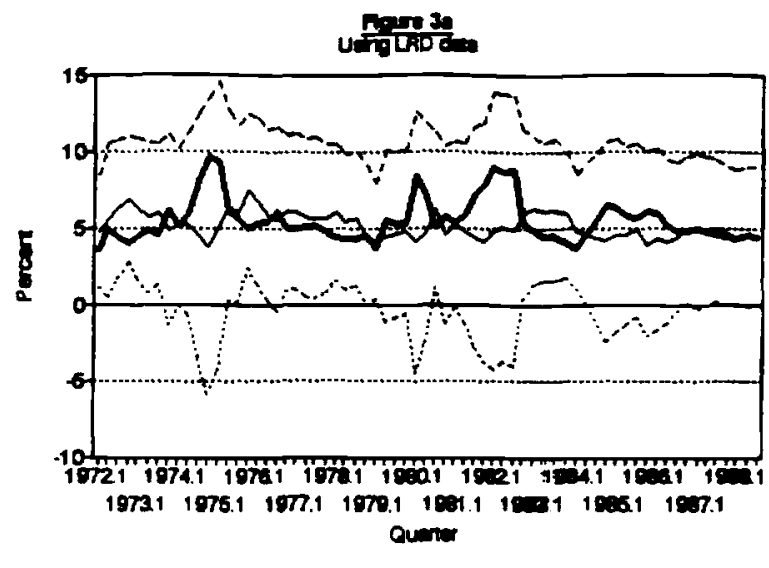

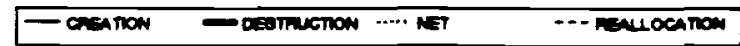

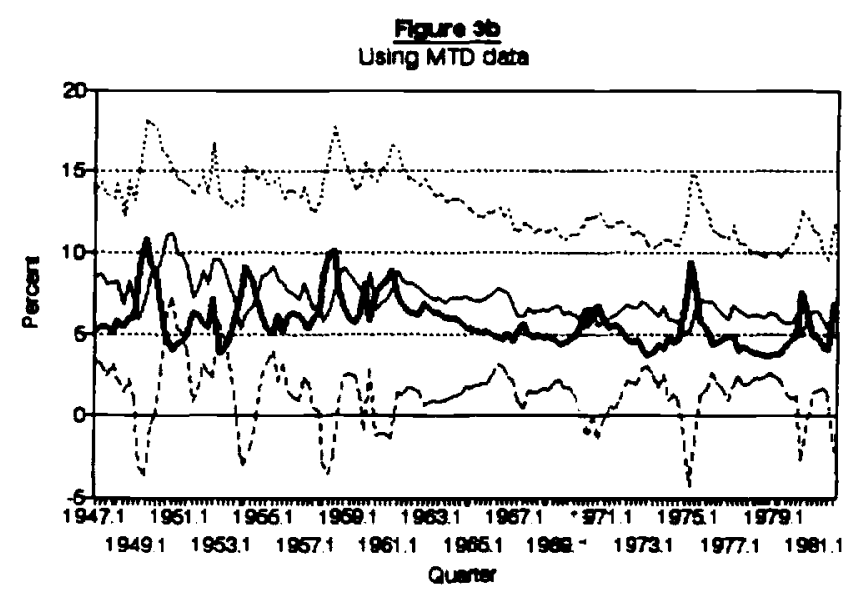

- CREATION DESTRUCTON --- NET …. RENLLOCATION

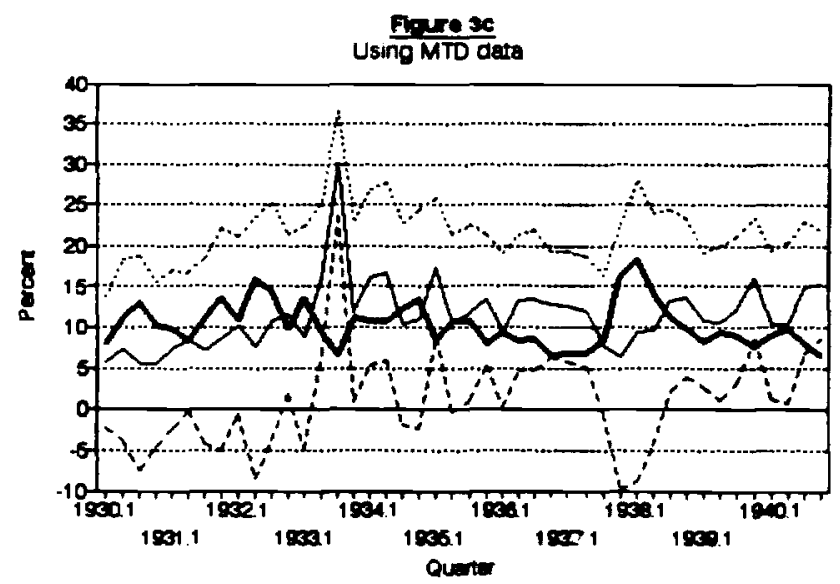

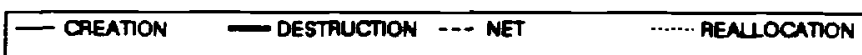




\section{Figure 4}

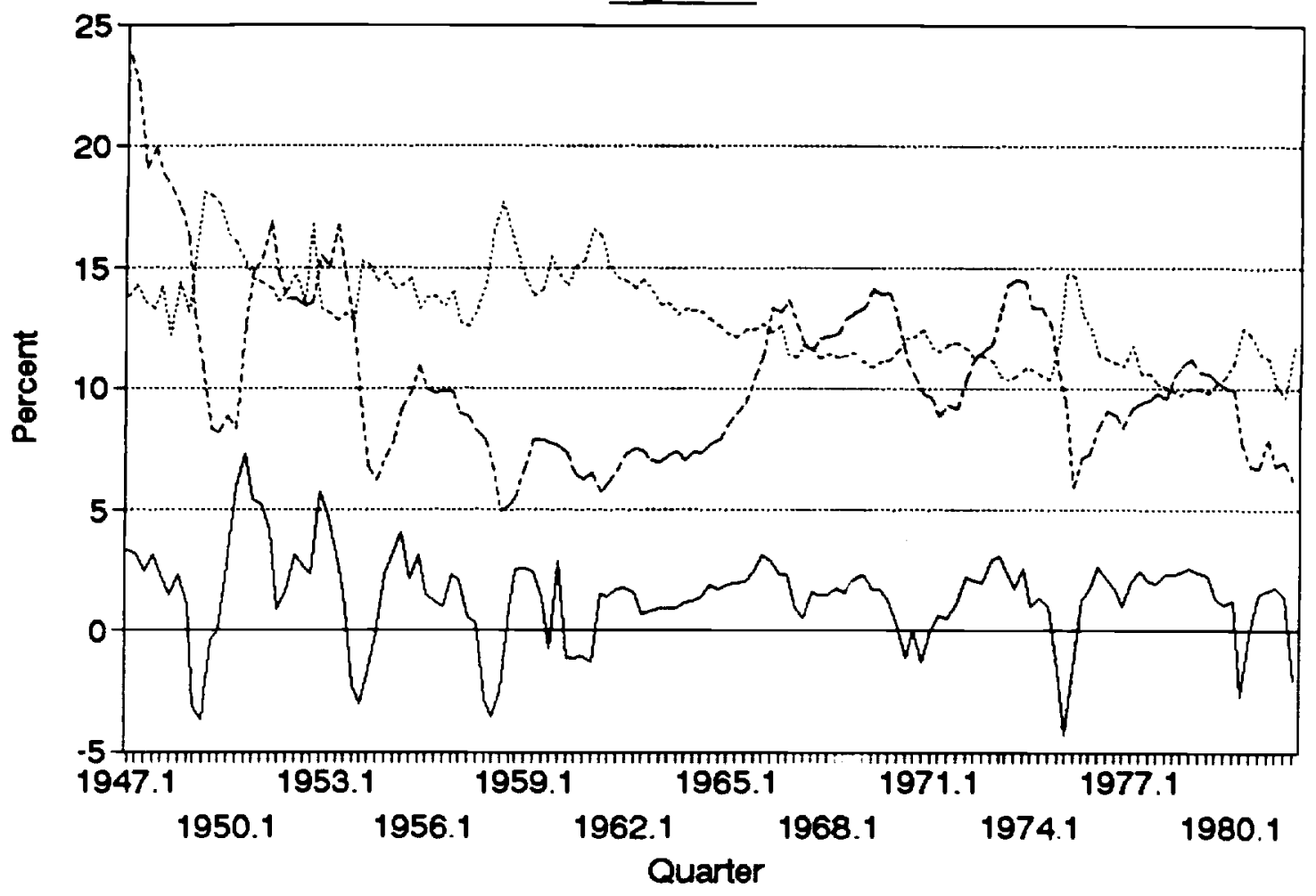

NET EMP GROWTH …… JOB REALLOCATION -...- OTHER TURNOVER 
Figure 5

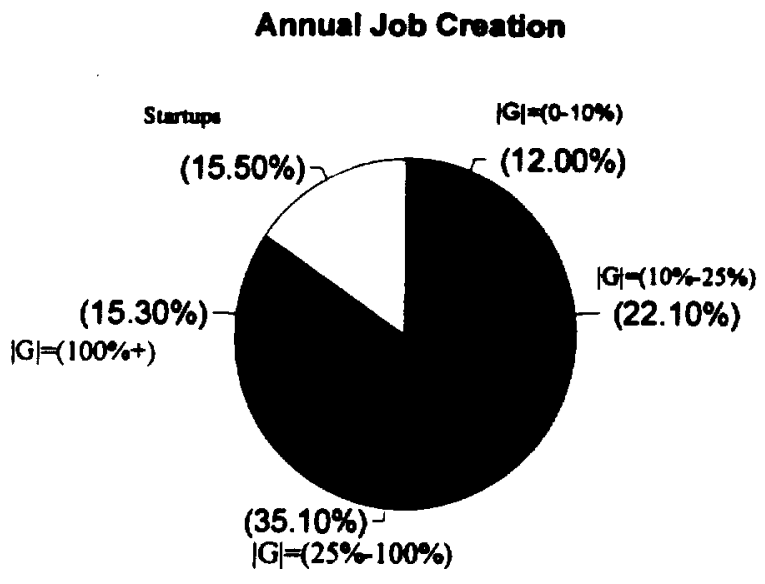

Annual Job Destruction

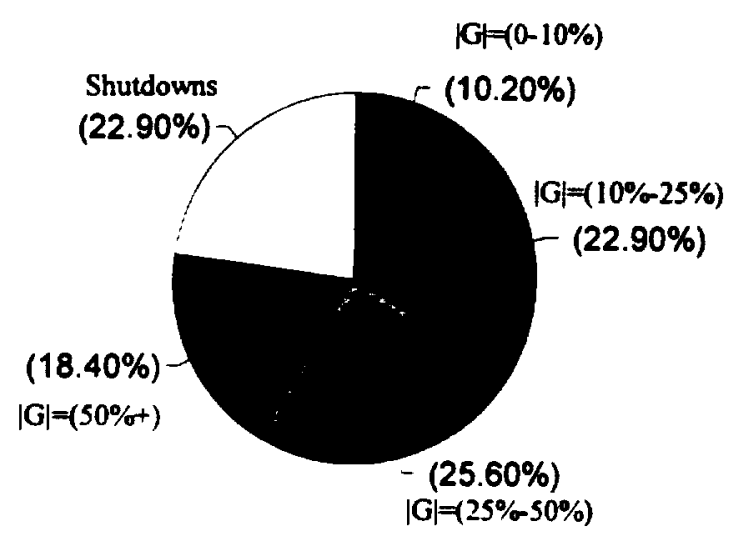

Quarterly Job Creation

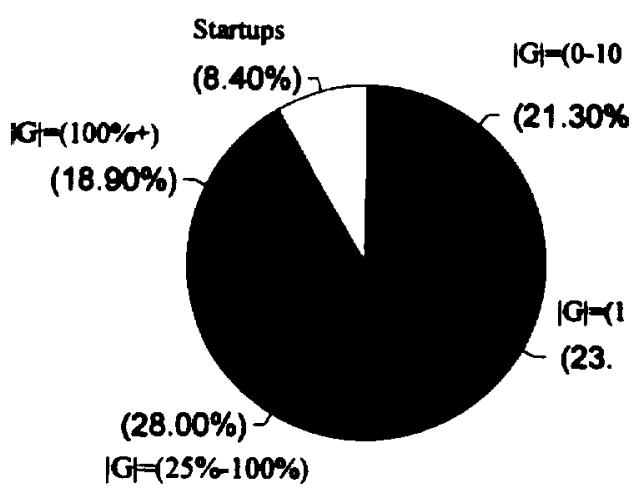

Quarterly Job Destruction

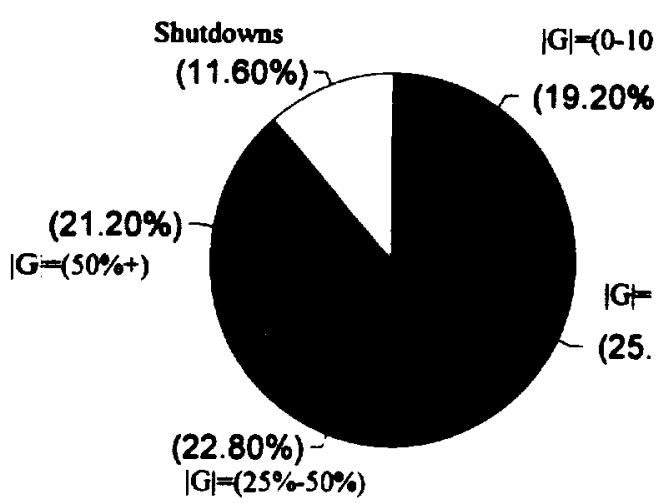




\section{Unemployment Flows and Gross Job Flows
Job Flows and Unemploymont Flows}

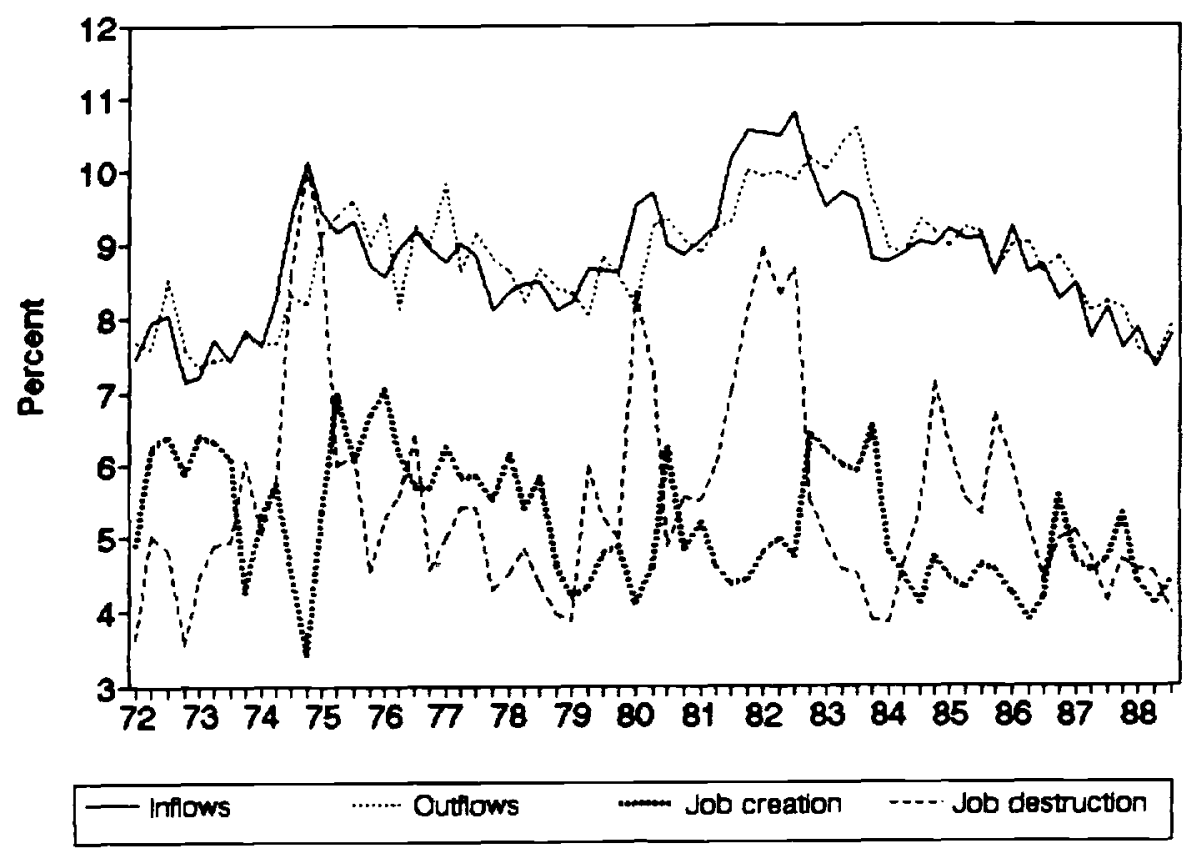

Note: Job creation and destruction are measured as percentages of employmem; unemployment flows are measured as percentages of the labor force. 